

\section{Nebraska Statewide Wind Integration Study: Executive Summary}

\section{April 2008 - January 2010}

EnerNex Corporation

Knoxville, Tennessee

Ventyx

Atlanta, Georgia

Nebraska Power Association

Lincoln, Nebraska

NREL Technical Monitor: Brian Parsons

Prepared under Subcontract No. AAM-9-89030-01

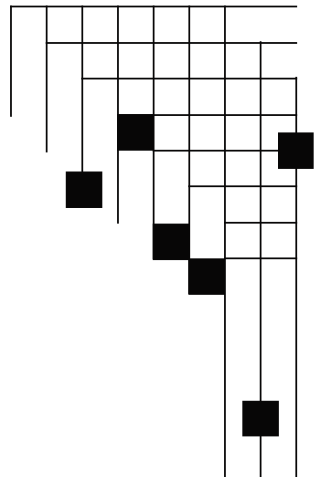




\section{NOTICE}

This report was prepared as an account of work sponsored by an agency of the United States government. Neither the United States government nor any agency thereof, nor any of their employees, makes any warranty, express or implied, or assumes any legal liability or responsibility for the accuracy, completeness, or usefulness of any information, apparatus, product, or process disclosed, or represents that its use would not infringe privately owned rights. Reference herein to any specific commercial product, process, or service by trade name, trademark, manufacturer, or otherwise does not necessarily constitute or imply its endorsement, recommendation, or favoring by the United States government or any agency thereof. The views and opinions of authors expressed herein do not necessarily state or reflect those of the United States government or any agency thereof.

Available electronically at http://www.osti.gov/bridge

Available for a processing fee to U.S. Department of Energy and its contractors, in paper, from:

U.S. Department of Energy

Office of Scientific and Technical Information

P.O. Box 62

Oak Ridge, TN 37831-0062

phone: 865.576 .8401

fax: 865.576 .5728

email: mailto:reports@adonis.osti.gov

Available for sale to the public, in paper, from:

U.S. Department of Commerce

National Technical Information Service

5285 Port Royal Road

Springfield, VA 22161

phone: 800.553 .6847

fax: 703.605.6900

email: orders@ntis.fedworld.gov

online ordering: http://www.ntis.gov/ordering.htm

This publication received minimal editorial review at NREL 


\section{Foreword}

This work is a result of the U.S. Department of Energy's (DOE) Wind Program and the National Renewable Energy Laboratory's (NREL) interest in advancing the understanding of wind integration impacts in the Western Area Power Administration's (WAPA) service area and among consumer-owned electric power cooperatives. The DOE through NREL provided cost-share support to the Nebraska Power Association (NPA) utilities to help carry out the program objectives of this wind integration study.

NREL's expectation was that the integration study should incorporate the best practices for performing such a study, including the assessment of wind's impact in the different time scales (regulation, load following, and unit commitment/scheduling) using highquality wind speed and/or wind power data.

The NPA is deeply appreciative of this learning opportunity afforded by the financial and technical support of NREL as provided to this study. The study process and results will be an aid in preparing for the rapidly developing wind future of Nebraska and its participation in regional markets. Further, the NPA is appreciative of the dedicated and talented work of the consultant team of EnerNex Corporation and Ventyx, Inc. Representatives of NREL, the consultants, and the rest of the Technical Review Committee (TRC) are listed in Appendix Section 8.1. Finally, the NPA thanks all members of the TRC and the observers for their steady attention, cooperative efforts and creative thinking. The NPA does not make any representations regarding use of the information beyond the context presented in this report.

WAPA offers this statement: "Western appreciated the opportunity to participate in this study. The results and conclusions offer insight as related to potential impacts/benefits resulting from the integration of large quantities of wind generation. Further, Western concurs with the statements contained in Section 7.2.1, in that Western does not make any representations regarding use of the information beyond the context presented in this report."

The National Renewable Energy Laboratory and the Nebraska Power Association do not make any representations regarding use of the information in this report beyond the context presented in this report. 


\section{Table of Contents}

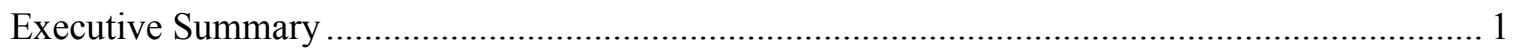

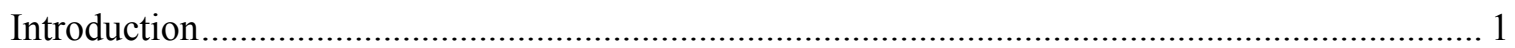

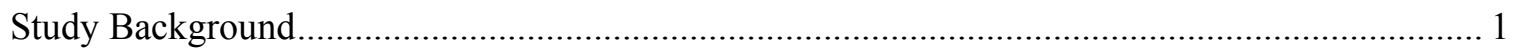

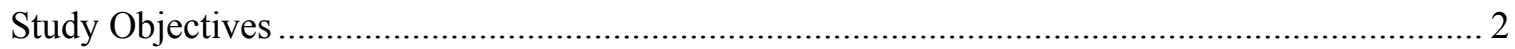

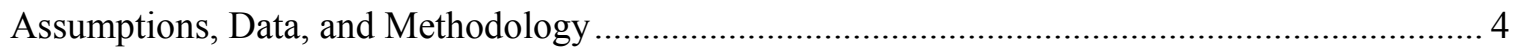

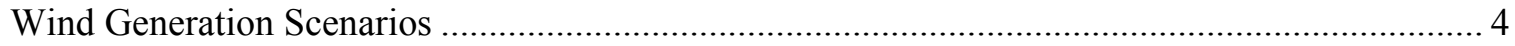

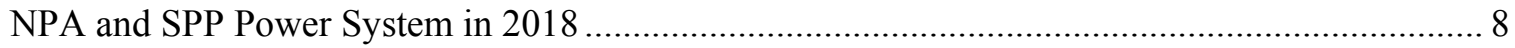

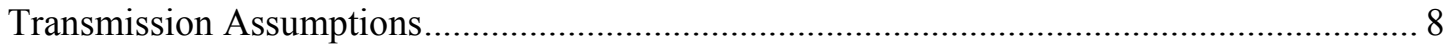

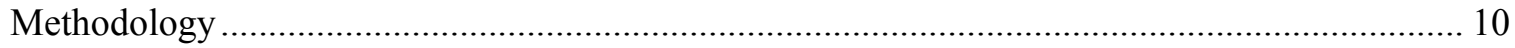

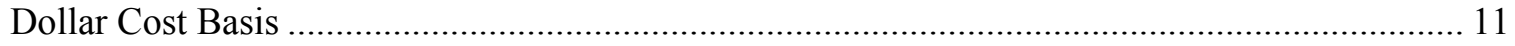

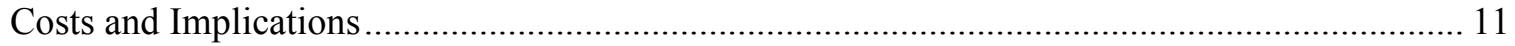

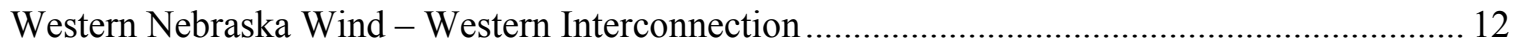

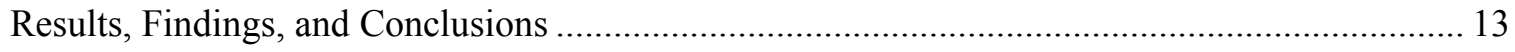

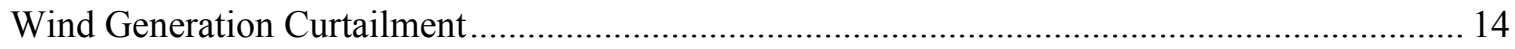

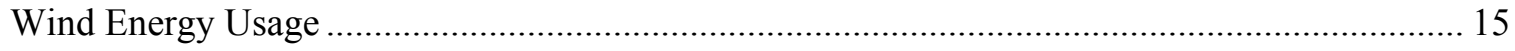

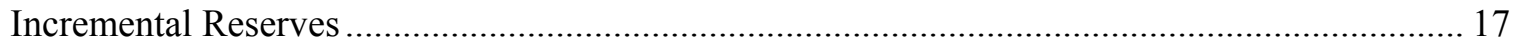

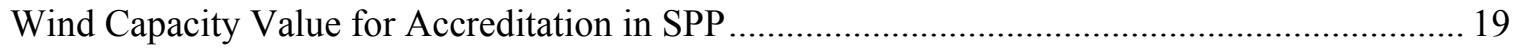

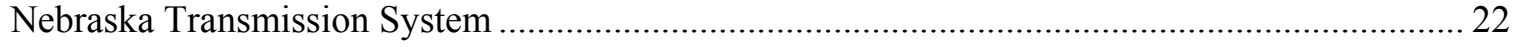

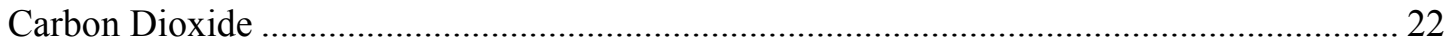

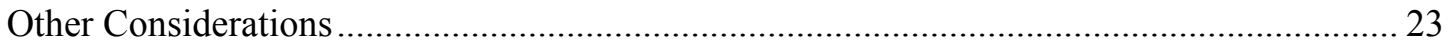

Total Costs (annual amounts in 2018 and assuming REC price of zero) ................................ 23

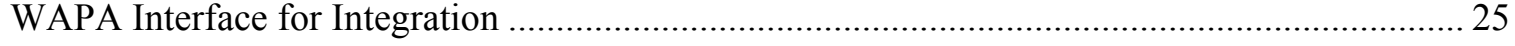

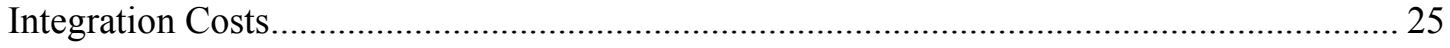

Wind Integration Costs - Methodology and Proxy Resource Selection ................................. 30

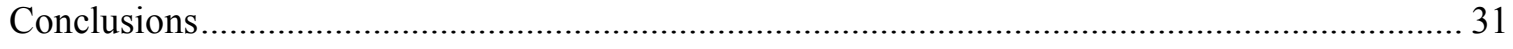

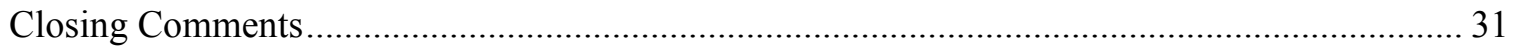

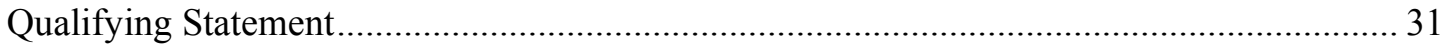

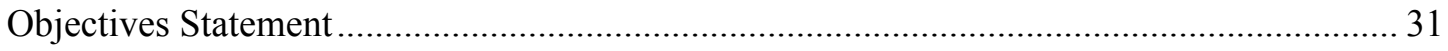

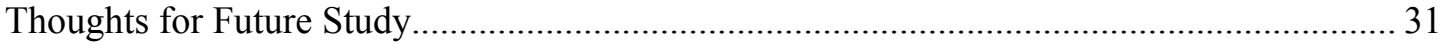




\section{List of Figures}

Figure 1: Nebraska 10\% Penetration Wind Site Map .......................................................6

Figure 2: Nebraska Wind Sites Added to 10\% Penetration Sites to Achieve 20\%

Penetration

Figure 3: Nebraska Wind Sites Added to 20\% Penetration Sites to Achieve 40\%

Penetration ...................................................................................................

Figure 4: Base Case Conceptual EHV Overlay ................................................................9

Figure 5: SPP Wind Generation Curtailment by Scenario (note: no curtailment in NPA)15

Figure 6: Nebraska Exports by Scenario ........................................................................16

Figure 7: Monthly NPA Wind Capacity Value Estimates by Scenario ..............................21

Figure 8: Monthly SPP (non-NPA) Wind Capacity Value Estimates by Scenario ............21

Figure 9: Monthly SPP with NPA Wind Capacity Value Estimates by Penetration.........21

Figure 10: Total SPP Cost Estimates (including Nebraska) in \$2018 millions - Cap \& Trade Regulation with 117.7 M s-ton Free Allowances, REC $=\$ 0, \operatorname{RES}($ wind) $=$ $12.4 \%$

Figure 11: Change in Nebraska Generation with Incremental Reserve Requirements and Additional Uncertainty due to Wind Generation ("actual” case) ..........................26

Figure 12: SPP (including Nebraska) Normalized Wind Integration Costs (shaped proxy) by Scenario and Wind Year for 2018 Conditions shown both in 2018\$ (top) and $2009 \$$ (bottom)

Figure 13: SPP (including Nebraska) Integration Costs Using Different Proxy Resources for 2018 Conditions shown both in $2018 \$$ (top) and $2009 \$$ (bottom). .29 


\section{List of Tables}

Table 1: Characteristics of Wind Penetration (Pen) for Study .......................................4

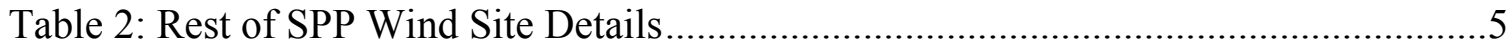

Table 3: Wind Generation Penetration ...................................................................................

Table 4: Detailed Results for Base Scenarios - all dollars are 2018\$ .............................14

Table 5: Regulating Reserve Requirements for Study Scenarios .................................18

Table 6: Regulating Reserve Requirements for NPA as a Single Balancing Authority and

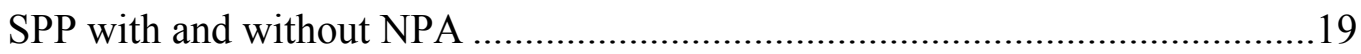

Table 7: Estimated Capacity Accreditation per SPP Methodology for Wind Generation

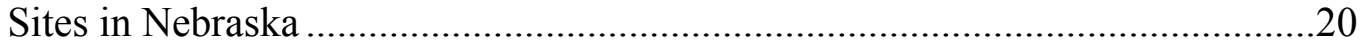

Table 8: Monthly Capacity Values for Aggregated Nebraska Wind Generation Scenarios

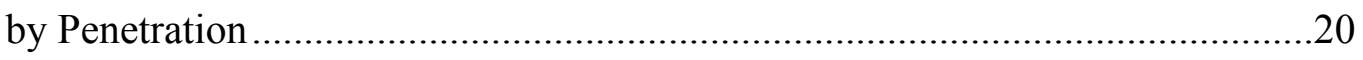

Table 9: Number of Nebraska Branches at or Near Limits ............................................22

Table 10: Shaped and Sub-period Block Proxy Analysis at 10\% and 20\% Wind

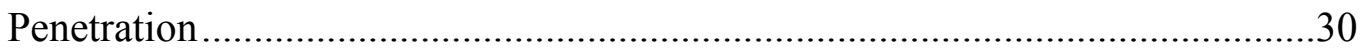




\section{Executive Summary}

\section{Introduction}

Wind generation is a source of electric energy that, in sufficient quantity, can cause concern for the operation of the bulk power system because of the variability and uncertainty of the wind. Most short-term planning and operational functions supporting the electric power grid are centered on supply resources that have capacity attributes - i.e. they can be dispatched (controlled up and down) to a specified power level for a specified period of time. The need to maintain very high levels of system reliability reinforces the preference in operations toward resources having capacity attributes. Wind generation usually has relatively low capacity value at system peak.

The characteristics of wind generation increase the variability of the net demand in the balancing area and the uncertainty about the net demand over operational planning horizons - e.g. next hour, next 24 hours beginning at midnight, etc. Managing a system with significant wind generation requires conventional resources to potentially "work a little harder". Increased costs are a consequence of the additional duties performed by conventional generators.

Over the past decade, many "wind integration" studies have been performed to quantify the operational impacts of wind generation.

Wind generation resources in Nebraska will play an increasingly important role in the environmental and energy security solutions for the state and the nation. In a reference document entitled "Renewable Energy Background and Outlook for Nebraska Electricity Consumers" , the Nebraska Power Association utilities recognized the growing need for a specific study of wind generation in the state.

This Nebraska Statewide Wind Integration Study provides that initial study.

\section{Study Background}

The Nebraska Power Association (NPA) (www.nepower.org) is a voluntary organization that represents all segments of the Nebraska power industry: municipalities, public power districts, public power and irrigation districts, and cooperatives engaged in generation, transmission, and/or the distribution of electric energy in the nation's only totally public power state.

The organization represents approximately $28,248 \mathrm{GWh}$ of annual retail load (2007 value - DOE) served by approximately 9,000 MW of generation capacity (including capacity associated with out-of-state purchases and sales). Six Nebraska utilities own and operate or purchase the output from a total of $152 \mathrm{MW}$-nameplate of wind generation projects in

\footnotetext{
${ }^{1}$ Dated December 28, 2007, downloadable from www.nepower.org/NPA\%20Report.pdf.
} 
five separate locations spread across the state. During 2009, power purchase agreements were completed for two new wind generation plants totaling $102 \mathrm{MW}$. Negotiations are under way to add more wind generation and still more wind additions are planned for later on according to the state utility integrated resource plans.

In April of 2008, NPA submitted a proposal to and received an award from the U.S. Department of Energy through the National Renewable Energy Laboratory for funding to conduct a state-wide wind integration study.

Nebraska electric utilities, large and small, are represented directly or indirectly by their power supplier in this study of wind integration effects to the public power system in Nebraska. Qualified and interested regional and national entities were invited to participate as observers or as active members of the Technical Review Committee. This Nebraska Statewide Wind Integration Study (Study) will help Nebraska implement wind energy in an intelligent manner, while maintaining Nebraska's success in operating a reliable and economical ( $5^{\text {th }}$ lowest state in 2007 at 6.28 cents per $\mathrm{kWh}$ ) electrical system and achieving the diversity of a significant state-wide renewable portfolio.

Of significant interest to NPA was the opportunity to work directly with the U.S. DOE's Wind Program, NREL, and WAPA not only because of their expertise, but also as an opportunity to foster regional solutions to wind integration issues.

Three balancing areas are fully represented: Nebraska Public Power District, Omaha Public Power District, and the Lincoln Electric System. Additionally all of the Nebraska utilities, small, medium, and large, are participating in the study through their NPA representation.

\section{Study Objectives}

Objectives of the work to be done were established by NREL and supplemented by NPA. These include evaluations of:

- The impact of wind energy on system operations using synchronized wind and load data and state of the art analysis techniques.

- Wind energy penetration of at least $10 \%$, based on wind energy to total energy sales should be evaluated. Additional scenarios at higher penetrations are encouraged.

- A combination of statistical analysis and production simulation.

- The extent to which the Federal hydroelectric system can be used to help with cost-effective wind integration that is consistent with reliable system operation.

- Potential mitigation approaches that may include innovative markets, institutional arrangements within or between Balancing Areas, or physical response on an economic basis. 
Additional objectives include:

- Production of meaningful and supported results in coordination with a Technical Review Committee (TRC), which should include stakeholders and experts in wind integration analysis.

- Opportunity for Nebraska utilities to utilize the NREL/WAPA grant program to advance statewide wind development giving consideration not only to the integration impacts but also to making progress in finding relevant solutions in a multi-stakeholder process.

- Quantifying the expected wind integration costs using valid evaluation techniques, both sub-hourly and hourly and longer for Nebraska wind generation development.

- Involving outside experts and interested parties in order to advance team building for future Nebraska wind generation development and increasing the level of understanding among state leaders concerning wind integration issues for Nebraska.

- Building a database and utility expertise for ongoing improved in-house modeling of wind generation impacts for future studies. 


\section{Assumptions, Data, and Methodology}

\section{Wind Generation Scenarios}

Wind generation penetration levels equivalent to $10 \%, 20 \%$, and $40 \%$ of Nebraska retail electric energy sales in 2018 were defined as the targets for the study.

Using a variety of criteria, individual plants were selected from the NREL Mesoscale database $^{2}$. This database was created with funding from the Department of Energy through NREL and consists of production profiles for wind plants east of the Rocky Mountains. The resolution of the profiles is in ten-minute increments for the entirety of historical years 2004, 2005, and 2006. The database contains profiles for 580,000 MW of wind generation.

The "sites" selected correspond to general areas where wind generation facilities already exist, or where good wind resources have been identified. An attempt was made to include a diversity of wind resource regions in the state. It must be made clear that the site selection process is not intended to indicate where the best resources or potential projects exist, but rather to develop representative scenarios for study of their impact on the operation of the NPA system.

Characteristics of the aggregate wind generation in the defined scenarios are given in Table 1 as average values for 2004-2006. The existing wind generation facilities in Nebraska are considered to be included in and modeled as part of these data.

Table 1: Characteristics of Wind Penetration (Pen) for Stud
\begin{tabular}{|l|r|r|r|}
\hline NPA & $10 \%$ Pen & $20 \%$ Pen & $40 \%$ Pen \\
\hline Energy (GWh) & 4,523 & 8,855 & 16,831 \\
Capacity (MW) & 1,249 & 2,488 & 4,727 \\
Capacity Factor & 0.41 & 0.41 & 0.41 \\
Average Site Size (MW) & 250 & 311 & 430 \\
\hline
\end{tabular}

Figure 1 through Figure 3 provide specific locations (close to center of each dark circle in the figure) of the production profiles (wind sites) selected from the NREL database for the $10 \%, 20 \%$, and $40 \%$ penetrations.

Wind generation in areas adjacent to Nebraska can influence system operations within Nebraska. This is especially true with modern energy markets, where generating units are committed to operation and dispatched based on price signals. These signals are a function of load, transmission, and "stack" of available resources. With marginal costs nearly equal to zero, wind generation is a "price taker," which reduces locational pricing. If transmission capacity allows, prices are depressed across a wide region due to the

\footnotetext{
${ }^{2} \mathrm{http}: / /$ www.nrel.gov/wind/integrationdatasets/eastern/data.html
} 
delivery of wind energy to the grid. With transmission congestion, prices may only be depressed on a local or sub-regional basis.

Therefore, it is important to consider the likelihood of wind development outside of Nebraska, so as not to skew the study results. The assumption in this study is that wind generation penetration in the rest of SPP would be equivalent percentage-wise with that in Nebraska. Table 2 provides details of the assumed wind generation in the rest of SPP for each scenario as average values for 2004-2006.

Table 2: Rest of SPP Wind Site Details

\begin{tabular}{|l|r|r|r|}
\hline Rest of SPP & 10\% Pen & $20 \%$ Pen & $40 \%$ Pen \\
\hline Number of Sites & 7 & 18 & 33 \\
Energy (GWH) & 22,901 & 45,807 & 91,548 \\
Capacity (MW) & 6,256 & 12,596 & 25,431 \\
CF & 0.42 & 0.41 & 0.41 \\
Average Site Size (MW) & 894 & 700 & 771 \\
\hline
\end{tabular}

SPP (including NPA) has interconnections to other regional entities, including MISO/MAPP and WAPA. Still other areas farther east were also modeled. To account for wind generation in these areas, without a dramatic increase in the scope of this study, the reference wind generation scenario developed for the Eastern Interconnection Wind Integration and Transmission Study (EWITS) was employed as the wind scenario for these regions. This reference case represents wind penetration that achieves current renewable portfolio standards. The installed capacity of wind modeled in these regions is around 50,000 MW, as seen in Table 3, and is a constant for each of the study scenarios. These represent a wind penetration outside SPP of approximately $6 \%$. Holding external penetrations constant encourages more exports out of SPP for the $20 \%$ and $40 \%$ SPP penetration levels than if the penetrations in the external areas were increasing along with those inside SPP.

Table 3: Wind Generation Penetration

\begin{tabular}{|l|r|r|r|r|r|r|r|r|r|}
\hline \multirow{2}{*}{\multicolumn{1}{c|}{ Region }} & \multicolumn{3}{|c|}{$10 \%$ Penetration } & \multicolumn{2}{c|}{$20 \%$ Penetration } & \multicolumn{3}{c|}{$40 \%$ Penetration } \\
\cline { 2 - 9 } & \multicolumn{1}{|c|}{$\begin{array}{c}\text { Name } \\
\text { Plate }\end{array}$} & \multicolumn{1}{c|}{ CF } & $\begin{array}{c}\text { Reference } \\
\text { Energy }\end{array}$ & $\begin{array}{c}\text { Name } \\
\text { Plate }\end{array}$ & \multicolumn{1}{c|}{$\begin{array}{c}\text { CF } \\
\text { Energy }\end{array}$} & $\begin{array}{c}\text { Name } \\
\text { Plate }\end{array}$ & $\begin{array}{c}\text { Reference } \\
\text { CF } \\
\text { Energy }\end{array}$ \\
\hline NPA & 1,249 & $41 \%$ & 4,523 & 2,488 & $41 \%$ & 8,855 & 4,727 & $41 \%$ & 16,831 \\
SPP w/o NPA & 6,256 & $42 \%$ & 22,901 & 12,596 & $41 \%$ & 45,807 & 25,431 & $41 \%$ & 91,548 \\
PJM & 25,807 & $36 \%$ & 81,460 & 25,807 & $36 \%$ & 81,460 & 25,807 & $36 \%$ & 81,460 \\
MISO/MAPP & 19,547 & $36 \%$ & 61,700 & 19,547 & $36 \%$ & 61,700 & 19,547 & $36 \%$ & 61,700 \\
SERC & 3,615 & $36 \%$ & 11,410 & 3,615 & $36 \%$ & 11,410 & 3,615 & $36 \%$ & 11,410 \\
TVA & 1,397 & $36 \%$ & 4,410 & 1,397 & $36 \%$ & 4,410 & 1,397 & $36 \%$ & 4,410 \\
\hline Total & 57,871 & $37 \%$ & 186,405 & 65,450 & $37 \%$ & 213,642 & 80,524 & $38 \%$ & 267,359 \\
\hline
\end{tabular}




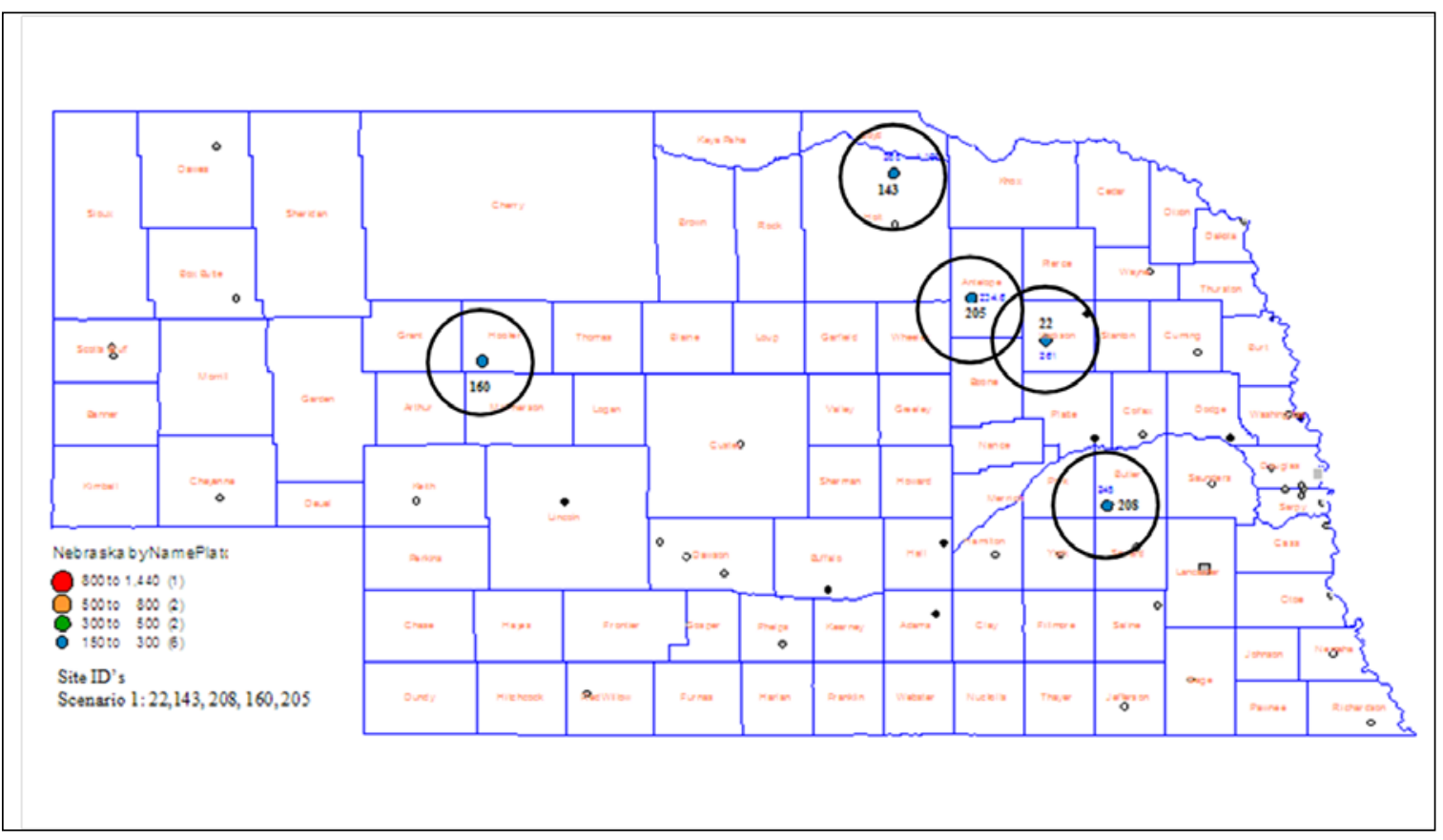

Figure 1: Nebraska 10\% Penetration Wind Site Map

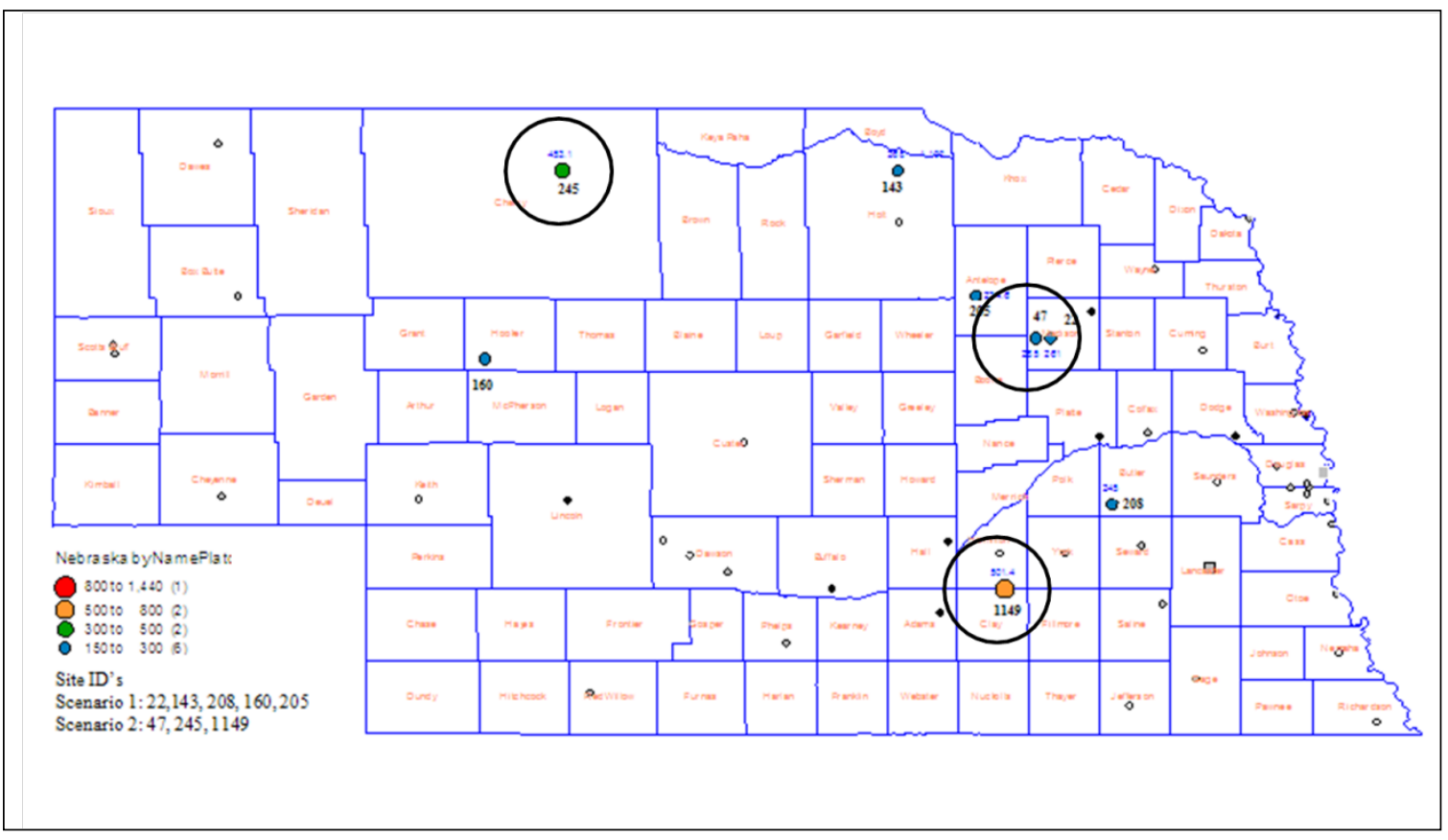

Figure 2: Nebraska Wind Sites Added to $10 \%$ Penetration Sites to Achieve 20\% Penetration 


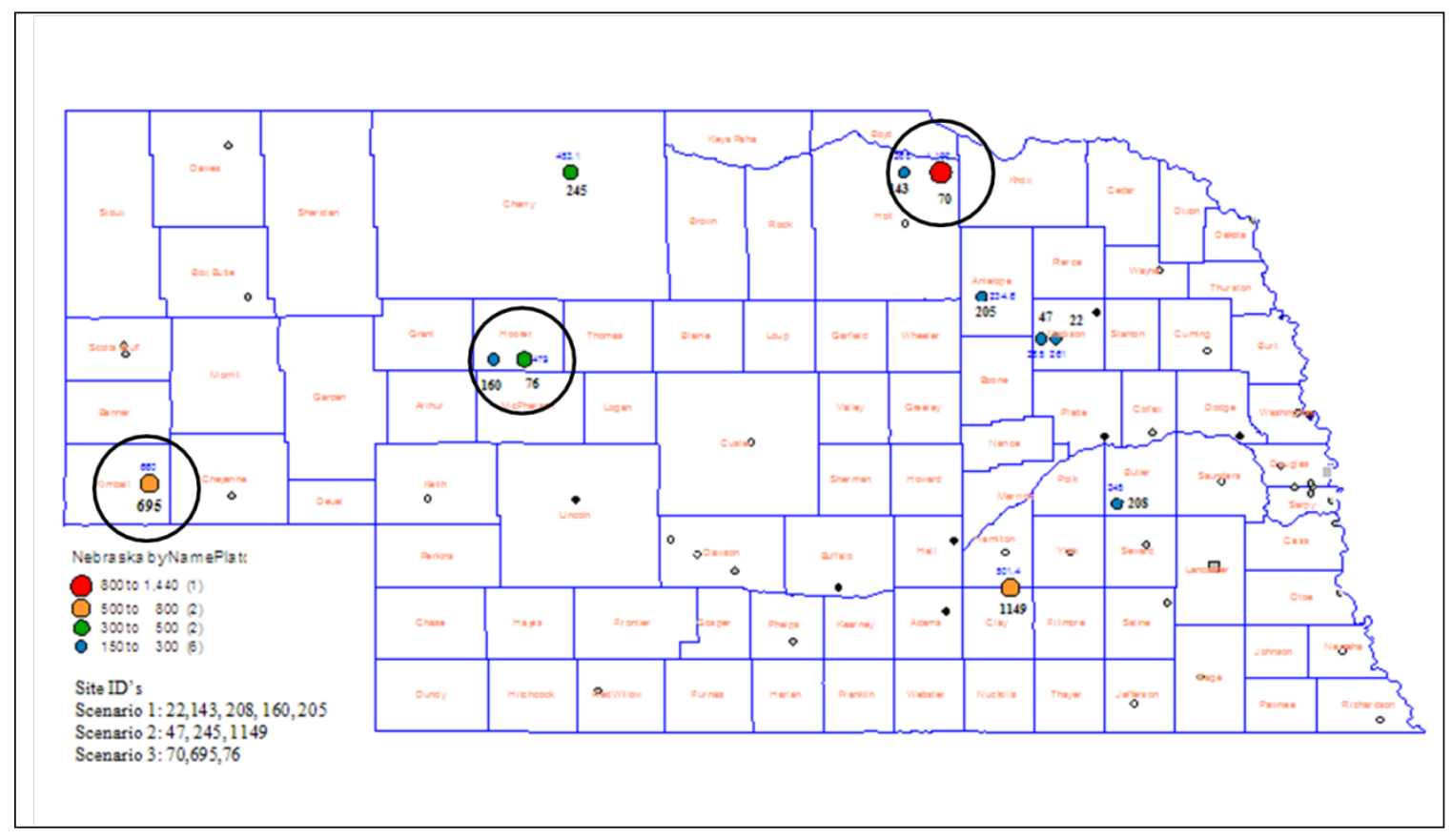

Figure 3: Nebraska Wind Sites Added to 20\% Penetration Sites to Achieve 40\% Penetration 


\section{NPA and SPP Power System in 2018}

An Eastern Interconnection power flow case for 2018 was the starting point for developing the detailed model to be used in this study. The power flow case had previously been developed and then used for the JCSP study and was also the starting point for the DOE/NREL Eastern Interconnection Wind Integration and Transmission Study (EWITS - www.nrel.gov/wind/systemsintegration/ewits.html).

The basic model data includes generating units, the transmission network, hourly bus loads, and wind generation profiles as described above. Completing the model from this relatively straightforward foundation requires many additional assumptions. These are detailed in the report.

NPA loads in the model were adjusted to match monthly peak demand and energy projected for 2018. Care was taken to retain the shape and pattern characteristics from historical years 2004 to 2006 to preserve correlation to the wind profile data for those same historical years.

Generating unit data in the base model was also audited and updated based on inputs from NPA members.

Finally, because NPA utilities became participants in the SPP market at the onset of this study, the modeling was structured to reflect this operational reality (the SPP day-ahead and ancillary services markets modeled are not in place today but are expected to operate in 2018). In the simulations described later, NPA generating units were committed and dispatched along with all other units in the SPP operating area. Hourly transactions of energy, both within the SPP market footprint and with external areas such as MISO, SERC, and TVA, were made on an economic basis. A "hurdle rate" between regions of $\$ 5 / \mathrm{MWh}$ was included in the interchange decision to reflect additional costs that needed to be overcome for interchange to take place between buyer and seller. Unit shares, whether ownership or participation transactions, were modeled for Nebraska purchases from out-of-state units and for Nebraska sales to out-of-state utilities.

\section{Transmission Assumptions}

The base model for the study contains a detailed representation of the transmission system, representing explicitly all buses at or above $115 \mathrm{kV}$. Planned transmission additions through at least 2013 are part of the power flow case from which the study model was derived. However, for the higher wind penetrations considered in the study, it was thought that transmission capacity could be an important issue and potentially lead to significant curtailment of wind generation without an adequate transmission build out.

The $10 \%$ wind penetration case (Scenario 1) was run with existing and currently planned/committed transmission facilities, as was an initial case at $20 \%$ penetration in NPA and the rest of SPP (Scenario 2). In addition, some localized transmission constraints were removed from the model without actually identifying specific 
transmission facilities necessary in operation to do so. A third case, (Scenario 3) again at $20 \%$ wind generation penetration, incorporated a substantial regional transmission expansion that has been under study at SPP for some time. With the addition of NPA utilities to SPP, the $765-\mathrm{kV}$ EHV overlay that constitutes the core of this plan was modified to loop through Nebraska as seen in Figure 4 below.

The EHV overlay was also initially used for the $40 \%$ wind penetration case (Scenario 4 ).

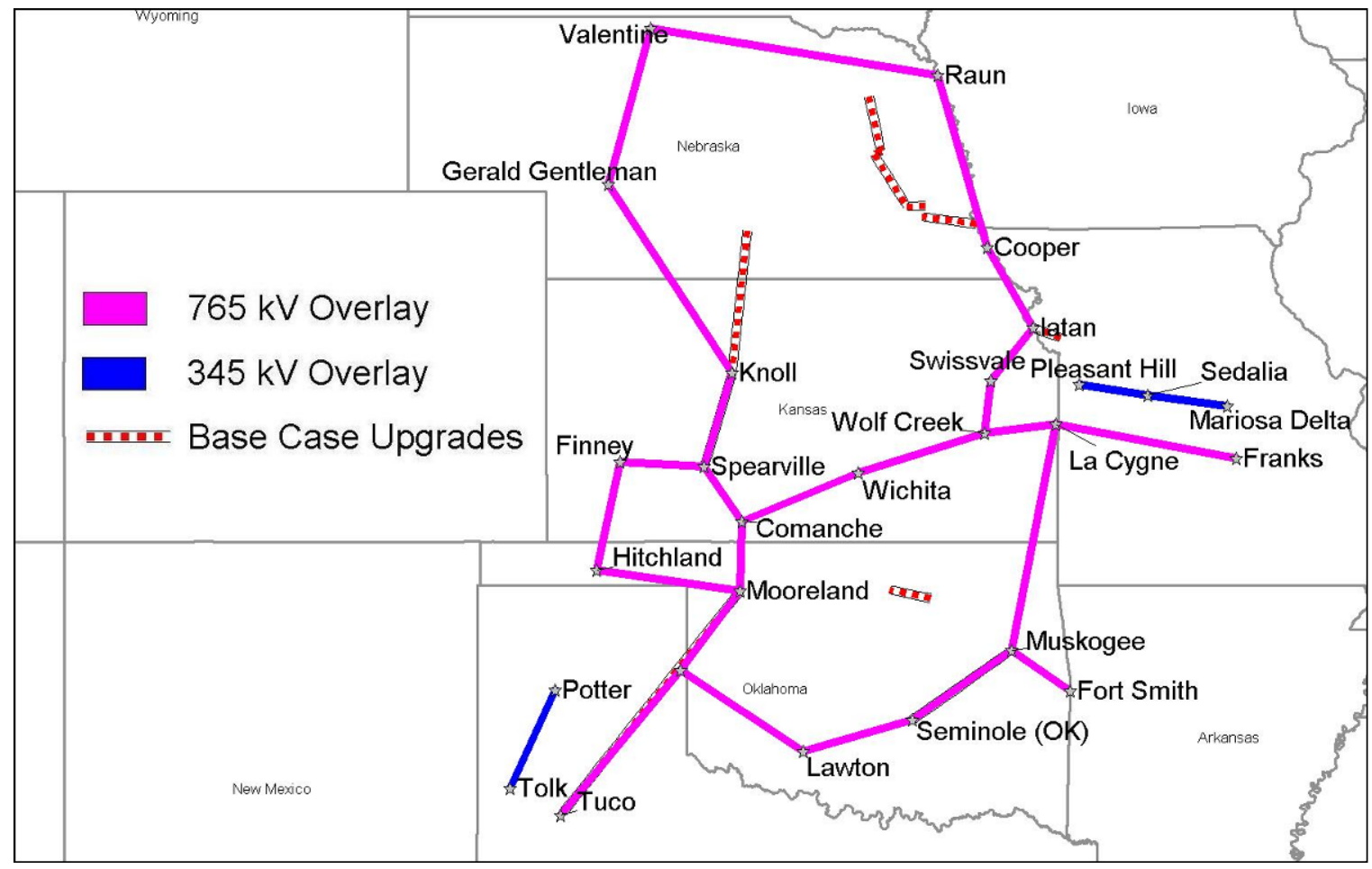

Figure 4: Base Case Conceptual EHV Overlay 


\section{Methodology}

Wind generation impacts on power systems operations are assessed through chronological production simulations. This is the preferred method for analyzing wind integration impacts, and has been used in nearly all of the major integration studies to date.

In the simulations, units are committed and dispatched to serve loads at each bus while honoring transmission constraints and recognizing the security needs of the system, while simultaneously adjusting generation to accommodate the delivery of wind energy to the system. Three full years with unique 8760 hour load and wind profile data representing the study year of 2018 are simulated. A nodal model is employed, where all transmission in the study area is represented explicitly, along with all generating units and loads at bulk delivery points.

With annual production simulations as the basic tool, a large number of cases are run to determine how increasing amounts of wind generation affect the utilization of other generating resources and the transmission system, consumption of fuel, and market prices for electric energy. In addition to analysis of the four base scenarios, a significant number of additional production simulation cases were run to explore how key variables or assumptions would affect the results.

A key goal of a wind integration study is to determine integration costs associated with wind generation. The additional variability and uncertainty attributable to wind generation increase the requirement for regulating reserves in real-time operations (above that already required for regulating load), and also introduce some additional inefficiency in the dayahead energy market due to increased errors in the aggregate forecast of load and wind generation. These general effects of wind generation are captured in the production simulations by a) optimizing the deployment of generating units (i.e. unit commitment) to forecasts of hourly wind and load for the next day rather than the "actual" quantities per the profiles mentioned above; and b) increasing the hourly reserve constraint (or requirement) consistent with the amount of wind generation during the hour. Additionally the shape or variability of the wind can be considered as an integration cost.

Integration costs are driven by changes in the use of the thermal generation fleet in response to the wind. Typically, the "actual" wind case simulation (including the effects of forecast error, incremental reserves and wind variability) will result in higher production costs than the "ideal" wind case (no forecast error, incremental wind reserves or wind variability). Given the makeup of Nebraska's thermal generation fleet, increased reserve requirements typically cause coal units to back down to carry reserves. This results in higher cost resources, particularly combined cycle units, being brought on to serve the energy previously generated by the coal units. These higher cost resources also respond to the faster ramps and forecast errors associated with wind.

The intent of these simulations is to mimic, as closely as possible, the assumed operational structure for SPP in the study year. It is assumed that the SPP energy markets 
in 2018 will consist of day-ahead and real-time (or sub-hourly) energy markets as well as an ancillary services market. All of these markets are not operational in SPP today.

Simulation outputs include the hourly operational profile of each generating unit in the model and hourly flows on all transmission lines in the model. Locational marginal prices (LMPs) and production costs are also key metrics.

\section{Dollar Cost Basis}

Throughout the report, dollars are given in 2018 nominal values unless otherwise noted.

Current cost numbers were escalated to 2018 using various rates depending on the particular cost element. Representation of results in 2018 nominal dollar terms is a common utility procedure and provides for the resulting (estimated) future relationship between such cost elements. However, for the purposes of potential comparison to other studies, normalized wind integration cost results are presented in 2009 dollar terms by deescalating the 2018 results to 2009 at $2.5 \%$ per year. Additionally, the cost value given in the Western Nebraska Wind - Western Interconnection is presented on a 2008 dollar basis.

\section{Costs and Implications}

A simplified methodology was developed to facilitate calculation of the total costs associated with each of the scenarios studied, as well as certain sensitivity cases. Because of the necessary simplifications, the total costs are useful as a relative metric to compare the cases. They do not represent a full accounting of all the details associated with each of the scenarios, and are very dependent on the assumptions established for this study.

The cost estimation procedure considers all of SPP including Nebraska, because of the shared-reserve modeling, and can be thought of in a step-wise manner as follows:

- A reference 2018 total cost is estimated with no $\mathrm{CO} 2$ regulation (cost) or federal Renewable Energy Standard or significant REC pricing.

- An incremental wind purchase cost is estimated for the increment of wind generation that is added above the existing amount now installed in the SPP.

- An incremental transmission cost is estimated for the increment of transmission line and substation facilities that will be needed as wind generation is added.

- A cost of CO2 emissions is included at various levels depending on the scenario description. The cap-and-trade estimates are patterned after the proposed Waxman-Markey bill. Alternative total cost results are presented for both capand-trade and tax regulation scenarios.

Essentially, the total cost estimate for a case then becomes:

- the reference cost

- plus incremental wind cost 
- plus incremental transmission cost

- minus the delta on PROMOD adjusted production cost (to convert from tax to cap-and-trade, if done for that case).

The list of assumptions used in these calculations is detailed in the report. Implications of this costing analysis are listed in the "Results, Findings, and Conclusions" section of this Executive Summary.

\section{Western Nebraska Wind - Western Interconnection}

The western-most area of the state of Nebraska is part of the Western Interconnection in the U.S.; the remainder of the state operates as part of the Eastern Interconnection. This artifact of history and the distribution of population across the lower 48 states has the effect of dramatically limiting the transfer of electric energy from eastern Nebraska to western Nebraska. There are several connections between the grids via back-to-back AC-DC-AC ties. Two of these connections are located in Nebraska. Transfer capability over these ties, however, is quite limited.

Western Nebraska is a very low load area, meaning that large amounts of wind generation will require transmission capability to "export" power out of the area to load centers. There is limited transmission capability, either to the east or to the west, due to commitments already in place for other resources. Consequently, it was impractical to incorporate those areas operating in the Western Interconnection (and their potential wind generation) directly into the analysis.

Given that the likely load center for wind in far western Nebraska would actually be in the Western Interconnection, a separate transmission evaluation was conducted to assess challenges for development of wind generation in this portion of the state.

In collaboration with the WAPA Rocky Mountain Region, the following topics pertaining to wind in the western portion of Nebraska in the Western Interconnection were addressed:

- Identification of how much wind generation could be injected into the western Nebraska transmission system without requiring transmission system upgrades.

- Determination of the transmission system upgrades required to add $300 \mathrm{MW}$ of wind generation in western Nebraska in the Western Interconnection. 
The focus for this part of the study was also nearer-term than the larger analytical effort, and looked at the 2012 time frame before considering 2018.

The analysis determined that the existing transmission network could connect and provide delivery for about $50 \mathrm{MW}$ of wind generation. Approximately $\$ 16$ million (2008\$) in transmission improvements would be necessary to interconnect $300 \mathrm{MW}$.

In the 2018 time frame, additional transmission improvements would also be required to connect $300 \mathrm{MW}$ of wind generation, although the details of the necessary upgrades differ from what was determined for the earlier year.

Wind integration costs, as computed for the eastern regions of the state and for the SPP market footprint, were not addressed in this component of the complete study.

\section{Results, Findings, and Conclusions}

Some details of the production simulations for the base scenarios are found in Table 4. The large volume of numerical results precludes a substantive discussion in this Executive Summary of the production simulation cases run and analyzed as part of this study effort. In this section, a review of the key study findings and conclusions, along with supporting tables, charts, and graphs from the body of the report is provided.

For brevity in referencing, four scenarios are numbered:

- Scenario 1: 10\% wind penetration in Nebraska (Figure 1) and the rest of SPP without the addition of an EHV transmission overlay.

- Scenario 2: 20\% wind penetration in Nebraska (Figure 1 and Figure 2) and the rest of SPP without the addition of an EHV transmission overlay.

- Scenario 3: 20\% wind penetration in Nebraska (Figure 1 and Figure 2) and the rest of SPP with the addition of a $765-\mathrm{kV}$ transmission overlay.

- Scenario 4: 40\% wind penetration in Nebraska (Figure 1, Figure 2, and Figure 3) and the rest of SPP with the addition of a $765-\mathrm{kV}$ transmission overlay.

Within each of the scenarios, the wind and load patterns for all three historical years (2004, 2005, and 2006) were also modeled as separate cases. Further, localized transmission additions necessary to handle the wind generation injections were not specifically identified but were implicitly assumed to be present as described in the Transmission Assumptions section. 
Table 4: Detailed Results for Base Scenarios - all dollars are 2018\$

\begin{tabular}{|c|c|c|c|c|c|c|c|c|c|c|c|c|}
\hline & \multicolumn{3}{|c|}{ Scenario 1} & \multicolumn{3}{|c|}{ Scenario 2} & \multicolumn{3}{|c|}{ Scenario 3} & \multicolumn{3}{|c|}{ Scenario 4} \\
\hline & 2004 & 2005 & 2006 & 2004 & 2005 & 2006 & 2004 & 2005 & 2006 & 2004 & 2005 & 2006 \\
\hline Load (TWh) - SPP & 265 & 265 & 265 & 265 & 265 & 265 & 265 & 265 & 265 & 265 & 265 & 265 \\
\hline Actual Wind (TWh) - SPP & 25.75 & 27.76 & 27.52 & 49.69 & 51.63 & 52.95 & 52.39 & 54.79 & 56.32 & 100.31 & 104.20 & 107.23 \\
\hline Ideal Wind (TWh) - SPP & 25.68 & 27.15 & 27.45 & 49.61 & 51.51 & 52.86 & 52.38 & 54.78 & 56.31 & 100.27 & 104.14 & 107.18 \\
\hline All Other Gen/Resources (TWh) - SPP & 250.72 & 249.41 & 250.05 & 237.34 & 236.55 & 236.09 & 237.17 & 236.29 & 235.83 & 214.41 & 212.45 & 211.00 \\
\hline Actual APC (\$M) - SPP & 14,815 & 14,685 & 14,655 & 13,162 & 13,013 & 12,924 & 12,772 & 12,579 & 12,462 & 9,759 & 9,488 & 9,334 \\
\hline Ideal APC (\$M) - SPP & 14,770 & 14,639 & 14,607 & 13,079 & 12,922 & 12,828 & 12,683 & 12,480 & 12,355 & 9,542 & 9,283 & 9,101 \\
\hline Delta APC (Actual minus Ideal) - SPP & 45 & 45 & 48 & 82 & 90 & 96 & 89 & 100 & 107 & 217 & 204 & 233 \\
\hline Integration Costs (\$/MWh) - SPP & 1.75 & 1.66 & 1.74 & 1.65 & 1.75 & 1.81 & 1.70 & 1.82 & 1.90 & 2.16 & 1.96 & 2.18 \\
\hline Wind Curtailment (\%) - Nebraska & $0 \%$ & $0 \%$ & $0 \%$ & $0 \%$ & $0 \%$ & $0 \%$ & $0 \%$ & $0 \%$ & $0 \%$ & $0 \%$ & $0 \%$ & $0 \%$ \\
\hline Wind Curtailment (\%) - Rest of SPP & $2 \%$ & $2 \%$ & $3 \%$ & $6 \%$ & $7 \%$ & $7 \%$ & $0 \%$ & $0 \%$ & $0 \%$ & $5 \%$ & $5 \%$ & $5 \%$ \\
\hline Exports (TWh) & 11.48 & 12.24 & 12.59 & 21.24 & 22.40 & 23.09 & 24.53 & 26.09 & 27.13 & 49.69 & 51.37 & 52.85 \\
\hline CO2 Emissions (Million Short Tons) & 203.07 & 202.83 & 202.75 & 193.22 & 192.93 & 192.46 & 194.53 & 194.22 & 193.59 & 175.64 & 174.14 & 172.58 \\
\hline SPP Wind Reserve (Max MW) & 884 & 853 & 852 & 1,538 & 1,540 & 1,542 & 1,538 & 1,540 & 1,542 & 3,003 & 3,041 & 3,034 \\
\hline SPP Wind Reserve (Avg MW) & 513 & 505 & 499 & 1,021 & 1,007 & 996 & 1,021 & 1,007 & 996 & 2,094 & 2,058 & 2,042 \\
\hline
\end{tabular}

Notes on Base Scenario Results:

- Reserves noted as "wind reserves" are the incremental regulating reserves associated with the additions of wind generation.

- $\quad \mathrm{APC}=$ Adjusted Production Cost

- SPP includes NPA unless otherwise noted

- Scenario 1: 10\% Wind Penetration

- Scenario 2: 20\% Wind Penetration

- Scenario 3: 20\% Wind Penetration w EHV Overlay

- Scenario 4: 40\% Wind Penetration w EHV Overlay

- Integration costs are based on shaped proxy resource. 


\section{Wind Generation Curtailment}

Assuming certain localized transmission line additions are made and Knoll-Axtell 345$\mathrm{kV}$ line is built, there was no significant wind generation curtailment in Nebraska in any case with or without the overlay. That is, all scheduled wind generation was accommodated by re-dispatching other generation and exporting excess wind energy, all within modeled transmission limits. As described in the Transmission Assumptions section, lines nearby to the wind injection points were allowed to overload for study simplicity rather than determine all the specific additions needed. Further the $40 \%$ case was only run with the overlay in place.

There was also no significant violation of Nebraska thermal unit minimums (i.e. dump energy) in any of the cases.

- With the wind dispatch price of $-\$ 40 / \mathrm{MWh}$ (assuming $\$ 15 / \mathrm{MWh}$ Renewable Energy Credit, REC and \$25MWh Production Tax Credit, PTC) wind has priority over other resources, i.e., other resources re-dispatch or even curtail before wind does.

- Access to large export markets was a key factor in accommodating the wind generation additions.

Although 20 major flow gates were monitored in Nebraska, it's possible that some local congestion was not captured in the analysis which could lead to curtailment.

In the rest of SPP for the base cases, wind curtailment was found to be:

- $2 \%$ at the $10 \%$ penetration without the overlay.

- $7 \%$ at the $20 \%$ penetration without the overlay.

- $0 \%$ at the $20 \%$ penetration with the overlay.

- $5 \%$ at the $40 \%$ penetration with the overlay. 
These results are summarized in Figure 5.

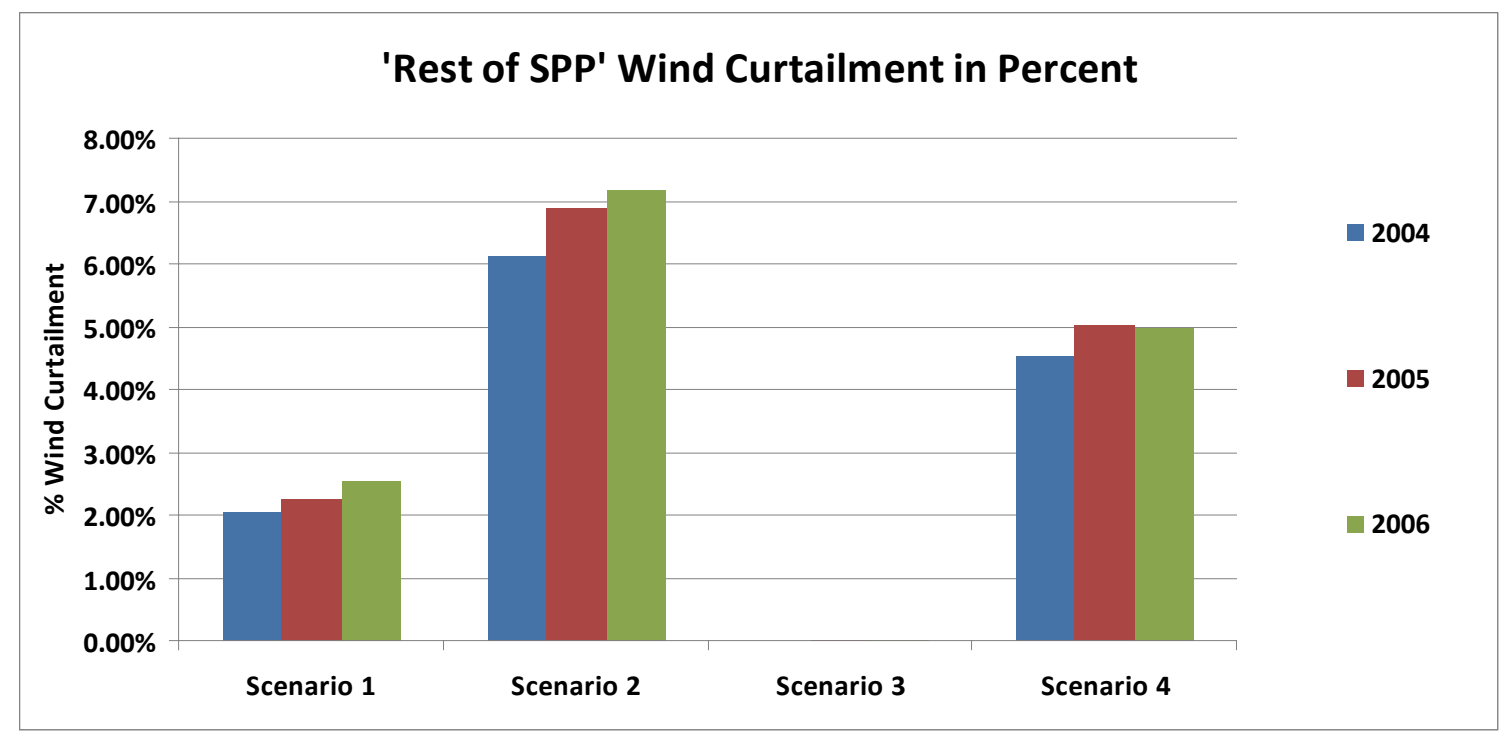

Figure 5: SPP Wind Generation Curtailment by Scenario (note: no curtailment in NPA)

\section{Wind Energy Usage}

Consistently as wind penetration increased, the study results indicate SPP (including Nebraska) increasing exports by approximately half of the amount of the wind generation increases. Specifically, for Nebraska only:

- Increasing $10 \%$ wind penetration to $20 \%$ wind penetration, Nebraska wind energy increases by $4.35 \mathrm{TWh}$ and exports increase by $3.20 \mathrm{TWh}(74 \%)$ when using the averages of the 3 wind years in the base cases of Scenarios 1 and 2, see Figure 6.

- Increasing $20 \%$ wind penetration to $40 \%$ wind penetration (with the EHV overlay), Nebraska wind energy increases by $8.12 \mathrm{TWh}$ and exports increase by 4.74 TWh $(58 \%)$ when using the averages of 3 wind years in the base cases of Scenarios 3 and 4, see Figure 6. 
Although it is impossible to determine the source of energy exported, the increased wind penetrations in Nebraska / SPP correspond to increased energy exports. Note that in areas external to SPP, the wind penetrations were held constant at a weighted $6 \%$ level across all of the SPP variations in penetration. As such, the external system had greater flexibility at the higher penetration scenarios to accept imports of wind than if it had the same higher penetrations as in SPP/NPA.

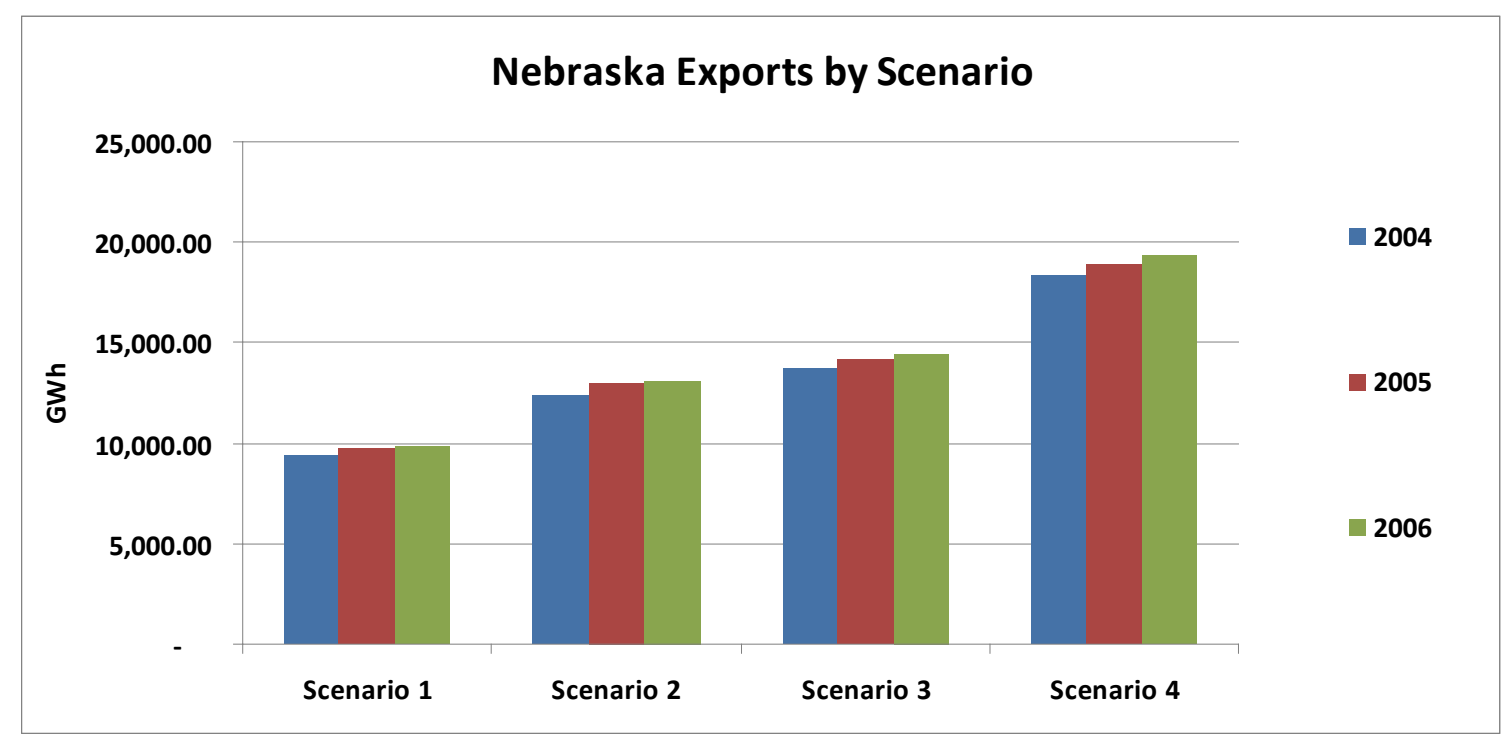

Figure 6: Nebraska Exports by Scenario 


\section{Incremental Reserves}

Wind generation has a substantial impact on the requirements for regulating reserves (an amount of spinning reserve responsive to Automatic Generation Control (AGC) that is sufficient to provide normal regulating margin) relative to what the load by itself requires. For the SPP market, 10\% wind energy in NPA and SPP will increase the average hourly requirement by around $500 \mathrm{MW}$. At $20 \%$, the incremental amount is about $1000 \mathrm{MW}$, and rises to about an additional $2000 \mathrm{MW}$ at $40 \%$ penetration, all are relatively linear.

There are costs associated with carrying these additional spinning reserves, which have been captured in the production simulations. It should also be noted that the incremental hourly amounts are small when wind generation is low and, obviously the largest at high levels of wind production. Under these conditions, however, conventional generation will be "unloaded" and freed up to contribute to the reserve needs.

The calculation of the increased regulating reserve requirement was done outside of, and prior to, the production simulations. The additional amounts of reserves are estimated by employing some statistical and mathematical analysis of higher resolution (10-minute intervals or less) wind and load data.

Results of these computations for the base scenarios are shown in. Because the requirements vary hourly with both wind and load, the average and maximum values for each year of the wind and load profile data are shown. At 10\% wind penetration in SPP, including NPA, the average value of the hourly regulating reserve more than doubled. At $40 \%$ wind penetration, regulating reserves requirements increase by over 7 times. 
Table 5: Regulating Reserve Requirements for Study Scenarios

\begin{tabular}{|c|c|c|c|c|c|c|c|}
\hline \multirow{2}{*}{$\begin{array}{c}\text { SPP with Nebraska } \\
10 \% \text { Penetraton }\end{array}$} & \multicolumn{2}{|c|}{ Load Only } & \multicolumn{2}{|c|}{ Load and Wind } & \multicolumn{2}{|c|}{$\begin{array}{l}\text { Delta Load and } \\
\text { Wind - Load }\end{array}$} & \multirow{2}{*}{$\begin{array}{c}\text { Wind } \\
\text { Nameplate } \\
\text { MW }\end{array}$} \\
\hline & Max & Average & Max & Average & $\operatorname{Max}$ & Average & \\
\hline 2004 profile & 533 & 301 & 1142 & 814 & 884 & 513 & 7,505 \\
\hline 2005 profile & 526 & 301 & 1146 & 806 & 853 & 505 & 7,505 \\
\hline 2006 profile & 528 & 295 & 1152 & 794 & 852 & 499 & 7,505 \\
\hline \multicolumn{8}{|l|}{ 20\% Penetration } \\
\hline 2004 profile & 533 & 301 & 1796 & 1322 & 1538 & 1021 & 15,084 \\
\hline 2005 profile & 526 & 301 & 1802 & 1308 & 1540 & 1007 & 15,084 \\
\hline 2006 profile & 528 & 295 & 1800 & 1291 & 1542 & 996 & 15,084 \\
\hline \multicolumn{8}{|l|}{ 40\% Penetration } \\
\hline 2004 profile & 533 & 301 & 3261 & 2395 & 3003 & 2094 & 30,158 \\
\hline 2005 profile & 526 & 301 & 3261 & 2359 & 3041 & 2058 & 30,158 \\
\hline 2006 profile & 528 & 295 & 3257 & 2337 & 3034 & 2042 & 30,158 \\
\hline
\end{tabular}

The increase in regulating reserves to manage the additional variability and short-term uncertainty attributable to wind generation is one of the major operating impacts. There are costs associated with the increased requirement and potential control performance degradation if adequate reserve capacity cannot be found among units in the operating area. Both of these issues are evaluated directly in the production simulations.

Table 6 illustrates one of the benefits of larger operating areas for managing wind generation. If NPA were operated as a single balancing area, not part of the SPP market, it would be responsible for providing regulating reserves for the wind generation in Nebraska. For the $10 \%$ case, the average hourly regulating reserve requirement for load and wind in the NPA balancing area on its own would be around $150 \mathrm{MW}$. This is in contrast with a $750 \mathrm{MW}$ requirement for the rest of the SPP market footprint. The value of aggregation can be clearly seen by comparing the SPP requirements from the two tables. Adding Nebraska - and its wind generation for the $10 \%$ case - to the SPP operating area (and ancillary services market) increases the regulating requirement by about $50 \mathrm{MW}$ (to $794 \mathrm{MW}$ ). This is less than the sum of the requirement for SPP and Nebraska operating separately $(742 \mathrm{MW}+148 \mathrm{MW}=890 \mathrm{MW})$. With more wind generation, the aggregation effect is even more pronounced. 
Table 6: Regulating Reserve Requirements for NPA as a Single Balancing Authority and SPP with and without NPA

\begin{tabular}{|l|r|r|r|r|r|r|r|}
\hline \multirow{2}{*}{$\begin{array}{l}\text { 10\% Penetration } \\
\text { 2006 profile }\end{array}$} & \multicolumn{2}{|c|}{ Load Only } & \multicolumn{2}{|c|}{ Load and Wind } & \multicolumn{2}{c|}{$\begin{array}{c}\text { Delta Load and } \\
\text { Wind - Load }\end{array}$} & $\begin{array}{c}\text { Wind } \\
\text { Nameplate }\end{array}$ \\
\cline { 2 - 7 } & \multicolumn{1}{|c|}{ Max } & Average & Max & Average & Max & Average & MW \\
\hline SPP with Nebraska & 528 & 295 & 1152 & 794 & 852 & 499 & 7,505 \\
SPP w/o Nebraska: A & 460 & 256 & 1111 & 742 & 821 & 486 & 6,256 \\
Nebraska alone: B & 75 & 45 & 216 & 148 & 177 & 118 & 1,249 \\
\hline Total A + B & 535 & 301 & 1327 & 890 & 998 & 604 & 7,505 \\
\hline
\end{tabular}

Delta Max Column represents the coincidental maximum delta of Load Only and Load and Wind

\section{Wind Capacity Value for Accreditation in SPP}

The SPP criteria for calculating monthly capacity value were used for these findings, because that is the criteria now applicable to Nebraska utilities. They are not based on an Effective Load Carrying Capacity methodology as are many criteria. Three years of Nebraska hourly wind data were correlated with corresponding 3 years of Nebraska hourly load.

The monthly capacity value for individual wind sites studied in Nebraska ranged from a $0.06 \%$ minimum to a $16.5 \%$ maximum, Table 7 . It is noteworthy that the two most common months in which Nebraska has its annual peak (July and August) are unfortunately the same two months in which the capacity values are the lowest.

When all the Nebraska wind sites were aggregated, the lowest monthly capacity values were observed in the summer months of June, July, and August, while the highest values were observed in April, May, September, and October, as shown for $40 \%$ penetration in Table 8 and in Figure 7. The aggregated minimum increased to $6.55 \%$ while the maximum remained at $16.5 \%$, Table $8,40 \%$.

For SPP (without Nebraska) the monthly capacity values for individual wind sites ranged in value from a $0.03 \%$ minimum to a maximum of $16.55 \%$. The lowest values were observed in December and January.

When the SPP (without Nebraska) wind sites were aggregated, the monthly capacity value minimum and maximum increased to $4.99 \%$ and $22.4 \%$ respectively, as shown in Figure 8 .

Aggregating all wind sites of Nebraska and SPP improved the monthly capacity values by increasing the minimum to $10.79 \%$ and maximum to $30.35 \%$, as shown in Figure 9 . This demonstrates the benefit of diversity across broader regions with increased wind capacity, assuming sufficient transmission exists. Although the data for November in these two figures stands out as atypical, nothing could be found in the NREL data that was obviously inappropriate. 
It is noted however, that the SPP accreditation criteria is currently applied to individual wind units only, rather than to an aggregation of plants.

Methods of calculating capacity credit for wind vary across the country and produce different results. A standardized method of calculating the capacity credit of wind is under investigation by FERC.

Table 7: Estimated Capacity Accreditation per SPP Methodology for Wind Generation Sites in Nebraska

\begin{tabular}{|l|r|r|r|r|r|r|r|r|r|r|r|}
\hline \multirow{2}{*}{ Nameplate } & \multicolumn{4}{|c|}{ NPA - 10\% Wind Sites } & \multicolumn{2}{|c|}{ NPA 20\% Wind Sites } & \multicolumn{2}{|c|}{ NPA 40\% Wind Sites } \\
\cline { 2 - 10 } & 261 & 268 & 240 & 235 & 245 & 285 & 453 & 501 & 1100 & 479 & 660 \\
\hline Site ID & 22 & 143 & 160 & 205 & 208 & 47 & 245 & 1149 & 70 & 76 & 695 \\
\hline Jan & $2.79 \%$ & $1.19 \%$ & $1.82 \%$ & $2.24 \%$ & $3.59 \%$ & $2.66 \%$ & $2.81 \%$ & $2.25 \%$ & $1.63 \%$ & $2.30 \%$ & $4.49 \%$ \\
Feb & $6.60 \%$ & $2.79 \%$ & $4.23 \%$ & $4.06 \%$ & $10.85 \%$ & $6.26 \%$ & $2.52 \%$ & $10.16 \%$ & $4.36 \%$ & $4.77 \%$ & $6.45 \%$ \\
Mar & $5.27 \%$ & $2.22 \%$ & $2.98 \%$ & $4.24 \%$ & $3.90 \%$ & $4.64 \%$ & $4.01 \%$ & $2.95 \%$ & $3.79 \%$ & $3.57 \%$ & $4.95 \%$ \\
Apr & $6.46 \%$ & $8.25 \%$ & $8.42 \%$ & $4.69 \%$ & $3.04 \%$ & $5.46 \%$ & $6.38 \%$ & $0.86 \%$ & $8.12 \%$ & $8.73 \%$ & $3.08 \%$ \\
May & $13.52 \%$ & $8.35 \%$ & $5.35 \%$ & $9.26 \%$ & $16.53 \%$ & $12.09 \%$ & $4.55 \%$ & $14.57 \%$ & $11.77 \%$ & $4.11 \%$ & $4.39 \%$ \\
Jun & $4.45 \%$ & $1.86 \%$ & $1.98 \%$ & $0.63 \%$ & $6.22 \%$ & $5.41 \%$ & $2.80 \%$ & $8.19 \%$ & $1.58 \%$ & $2.11 \%$ & $3.22 \%$ \\
Jul & $1.54 \%$ & $1.17 \%$ & $1.08 \%$ & $0.06 \%$ & $1.96 \%$ & $0.54 \%$ & $0.39 \%$ & $1.26 \%$ & $1.37 \%$ & $1.51 \%$ & $2.41 \%$ \\
Aug & $3.07 \%$ & $0.81 \%$ & $2.22 \%$ & $0.34 \%$ & $1.94 \%$ & $3.29 \%$ & $1.39 \%$ & $4.11 \%$ & $1.19 \%$ & $1.86 \%$ & $3.35 \%$ \\
Sep & $10.40 \%$ & $6.79 \%$ & $4.05 \%$ & $5.35 \%$ & $12.66 \%$ & $10.19 \%$ & $3.14 \%$ & $12.53 \%$ & $9.25 \%$ & $4.02 \%$ & $3.13 \%$ \\
Oct & $7.92 \%$ & $10.23 \%$ & $1.47 \%$ & $5.21 \%$ & $8.36 \%$ & $7.35 \%$ & $2.32 \%$ & $5.47 \%$ & $10.23 \%$ & $1.63 \%$ & $5.37 \%$ \\
Nov & $2.10 \%$ & $0.86 \%$ & $2.43 \%$ & $1.20 \%$ & $0.98 \%$ & $1.64 \%$ & $5.57 \%$ & $0.53 \%$ & $1.77 \%$ & $4.33 \%$ & $6.23 \%$ \\
Dec & $3.94 \%$ & $3.59 \%$ & $3.76 \%$ & $3.87 \%$ & $2.73 \%$ & $4.07 \%$ & $4.34 \%$ & $1.74 \%$ & $3.55 \%$ & $2.80 \%$ & $3.31 \%$ \\
\hline
\end{tabular}

Table 8: Monthly Capacity Values for Aggregated Nebraska Wind Generation Scenarios by Penetration

\begin{tabular}{|l|r|r|r|}
\hline \multirow{2}{*}{ Nameplate } & \multicolumn{3}{|c|}{ All Nebraska Sites } \\
\cline { 2 - 4 } & $10 \%$ & $20 \%$ & $40 \%$ \\
\cline { 2 - 4 } Jan & 1249 & 2488 & 4727 \\
Feb & $6.18 \%$ & $7.96 \%$ & $9.02 \%$ \\
Mar & $7.73 \%$ & $10.30 \%$ & $12.74 \%$ \\
Apr & $7.29 \%$ & $7.71 \%$ & $11.18 \%$ \\
Juy & $11.19 \%$ & $14.29 \%$ & $15.65 \%$ \\
Jul & $13.41 \%$ & $16.39 \%$ & $16.56 \%$ \\
Aug & $7.75 \%$ & $9.34 \%$ & $8.91 \%$ \\
Sep & $2.94 \%$ & $4.75 \%$ & $6.55 \%$ \\
Oct & $4.98 \%$ & $8.83 \%$ & $7.56 \%$ \\
Nov & $10.61 \%$ & $11.20 \%$ & $13.78 \%$ \\
Dec & $8.60 \%$ & $11.34 \%$ & $13.05 \%$ \\
Nec & $5.52 \%$ & $7.19 \%$ & $10.50 \%$ \\
\hline
\end{tabular}




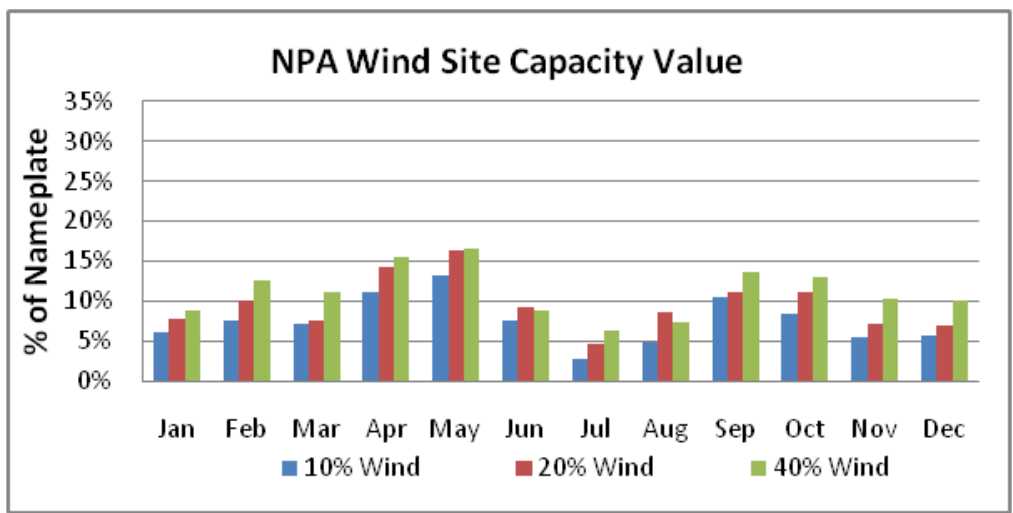

Figure 7: Monthly NPA Wind Capacity Value Estimates by Scenario

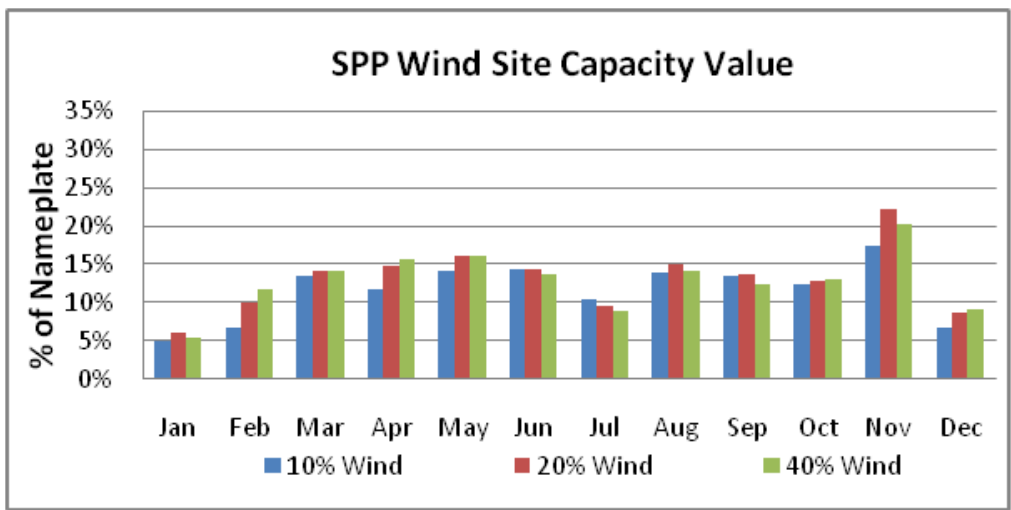

Figure 8: Monthly SPP (non-NPA) Wind Capacity Value Estimates by Scenario

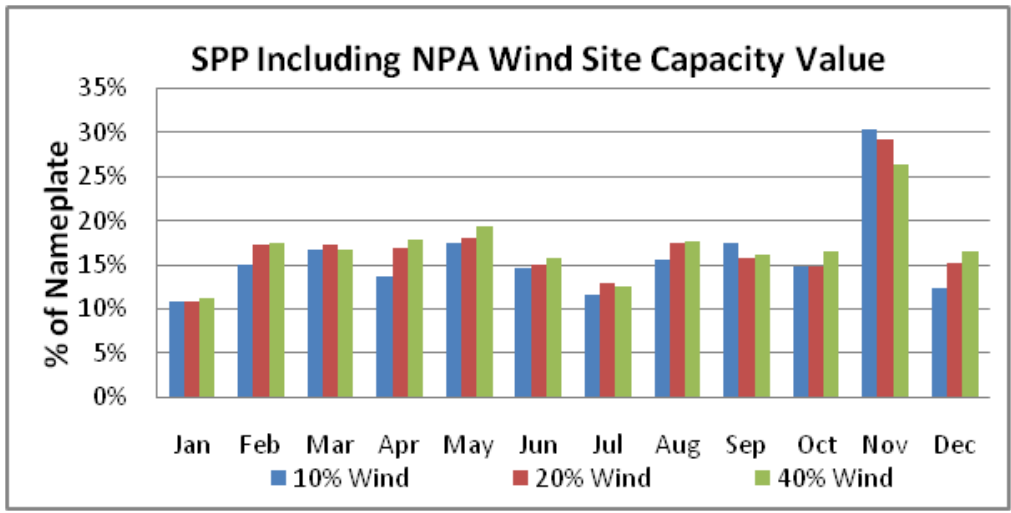

Figure 9: Monthly SPP with NPA Wind Capacity Value Estimates by Penetration 


\section{Nebraska Transmission System}

New transmission will be required to bring any significant new wind resources online.

The transmission system will be stressed with increased wind penetration. The transmission system expansion must be designed with wind expansion in mind to minimize those stresses.

- Twenty flow gates involving Nebraska were modeled and fifteen of them were constrained somewhat. They range from one hour to 4,970 hours out of the year depending on the scenario and flow gate. Nine flow gates had no constrained hours.

- Table 9 shows the number of non-monitored branches (not flow gates) in Nebraska that approached or exceeded their thermal limits by scenario using the $2006 \mathrm{wind} / \mathrm{load}$ patterns. In the model, these branches are $115-\mathrm{kV}$ to $345-\mathrm{kV}$ lines that are allowed to exceed limits in recognition that other transmission will need to be designed and installed to relieve these overloads.

- Specifically, the transmission system shows increased usage and risk of overloads as wind penetration increases, but those overloads decrease with the addition of transmission designed to deliver the wind energy (i.e., the $765-\mathrm{kV}$ overlay), as shown in Table 9. That is, in all four scenarios, overloads exceed limits as penetration increases without adding transmission. Conversely from Scenario 2 to Scenario 3, the numbers decrease with the addition of the overlay.

Table 9: Number of Nebraska Branches at or Near Limits

\begin{tabular}{|l|r|r|r|r|}
\hline & Scenario 1 & Scenario 2 & Scenario 3 & Scenario 4 \\
\hline Violations of Thermal Limit & 6 & 15 & 10 & 23 \\
\hline $\begin{array}{l}\text { Over 90\% of Thermal Limit (excludes } \\
\text { violations) }\end{array}$ & 6 & 11 & 4 & 2 \\
\hline $\begin{array}{l}\text { Over 80\% of Thermal Limit (excludes } \\
\text { violations and 90\% violations) }\end{array}$ & 15 & 15 & 11 & 10 \\
\hline $\begin{array}{l}\text { Total Non-monitored Branches over } \\
80 \% \text { of Thermal Limit }\end{array}$ & 27 & & & 35 \\
\hline
\end{tabular}

\section{Carbon Dioxide}

Increased wind penetrations result in lower $\mathrm{CO} 2$ emissions, as shown in Table 4.

- Nebraska CO2 emissions decrease by about $8 \%$ between the $10 \%$ wind case and the $40 \%$ wind case (using averages of 3 wind years).

- The rest of SPP decreases CO2 emissions by about $15 \%$ between the same cases (using averages of 3 wind years).

- Increased exports due to wind will offset emissions outside of SPP. 
A pure price penalty on $\mathrm{CO} 2$ is not very effective at reducing $\mathrm{CO} 2$ emissions in SPP, including Nebraska, (given the consistent expansion fleet modeled for all penetration levels) until the penalty gets very large (using 2006, Scenario 3 and its variations).

- A $\$ 25$ / short ton penalty reduced SPP CO2 emissions by about $2 \%$ from the no penalty case.

- A $\$ 50$ / short ton penalty reduced SPP CO2 emissions by about $6 \%$ from the no penalty case.

- A $\$ 120$ / short ton penalty reduced SPP CO2 emission by about $19 \%$ from the no penalty case.

Increased price penalties on $\mathrm{CO} 2$ result in decreased wind integration costs as more gas resources are committed due to $\mathrm{CO} 2$ penalties in both the ideal and actual cases that diminish the cost difference between coal and gas.

Significant carbon reductions through dispatch penalties or emissions caps result in huge increases in the use of natural gas for electricity. Combined cycle use in Nebraska increases by $138 \%$ in the CO2 reduction case ( $\$ 120$ /short ton) when compared to the base case ( $\$ 25 /$ short ton), increasing CC capacity factors to over $80 \%$.

\section{Other Considerations}

There would be some additional costs associated with managing wind generation not captured in these production simulations:

- Additional maintenance and forced outages and de-rates

- Degradation of heat rate from ramping, cycling, and range of operation

- Increase in emission rate per MWh production due to increased ramping that is not fully embodied in historical data that is used to determine modeled emission rates

- Other potential factors

Production simulation results could be used to make estimates for some of these factors, but that was not attempted in this study.

\section{Total Costs (annual amounts in 2018 and assuming REC price of zero)}

In most cases, two incentives for wind generation are being modeled: a production tax credit (PTC) and a carbon dioxide emission price. It is not likely that three incentives will exist in 2018. Though it is acknowledged that the PTC extends through 2012, but it is not certain that it would remain in 2018 after a federal Renewable Energy Standard is adopted.

The primary results of the total cost estimation process for SPP including Nebraska are shown in Figure 10. It illustrates four cost categories, in both bar chart and tabular form, for fifteen primary cases run on the 2006 wind and load patterns: incremental wind 
generation cost (cost above existing wind), incremental transmission, $\mathrm{CO} 2$ prices, and other costs (production and other fixed costs). For this set of cases, the total cost estimates for 2018 range from $\$ 23.7$ billion to $\$ 28.5$ billion, a $20 \%$ increase over the reference case to the $\mathrm{CO} 2$ reduction case identified as $\$ 50 /$ short ton $(\$ 120$ in the dispatch). If the $\mathrm{CO} 2$ regulation is a tax instead, the corresponding case is accordingly higher in cost.

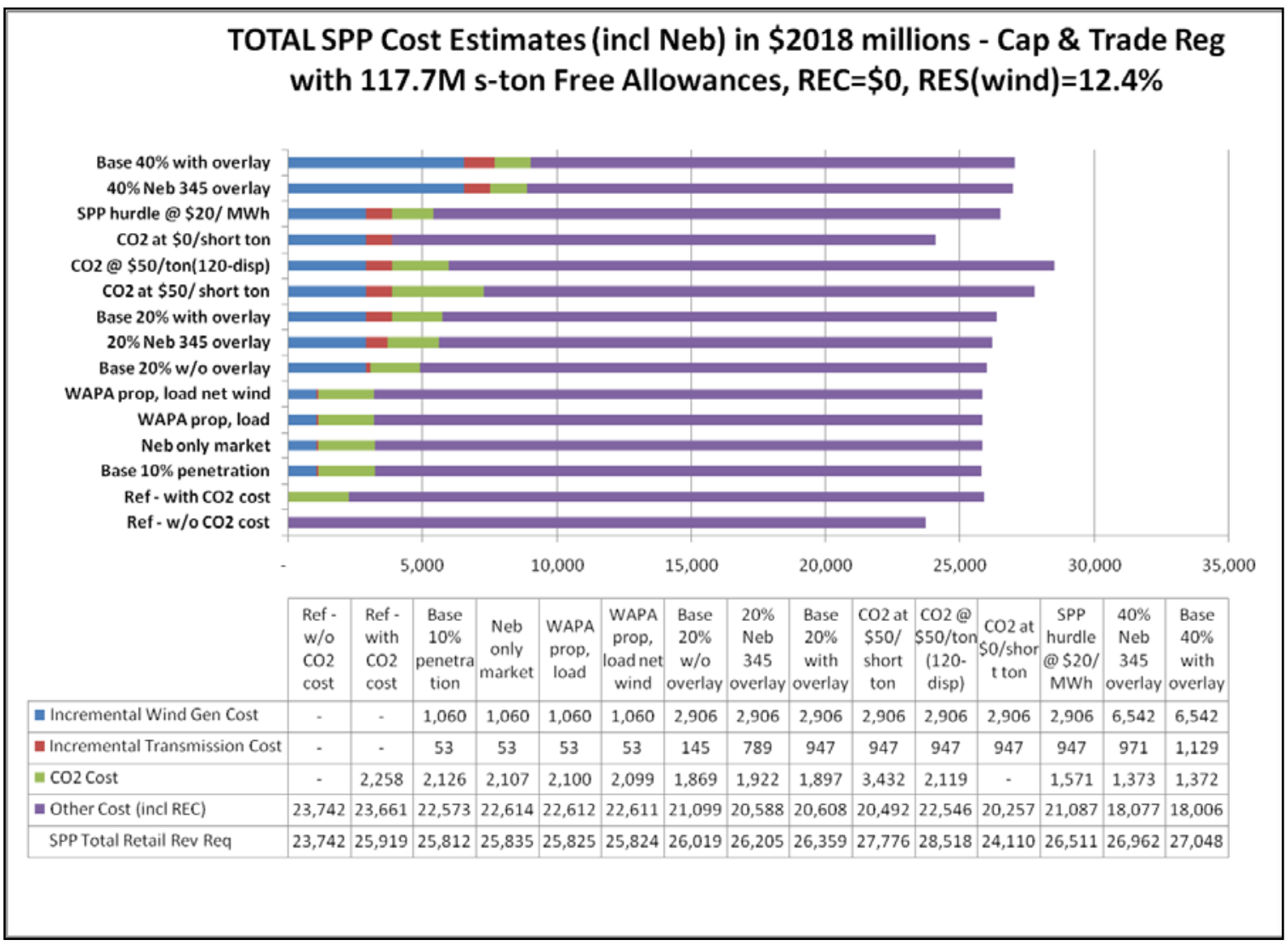

Figure 10: Total SPP Cost Estimates (including Nebraska) in \$2018 millions - Cap \& Trade Regulation with $117.7 \mathrm{M}$ s-ton Free Allowances, $\operatorname{REC}=\$ 0, \operatorname{RES}($ wind $)=12.4 \%$

The following observations and conclusions assume a Renewable Energy Credit (REC) price of $\$ 0$ :

- $\$ 25 /$ short ton $\mathrm{CO} 2$ price for cap-and-trade adds approximately $9 \%$ (or $\$ 2.2$ billion) to the total cost reference, which is estimated at $\$ 23.7$ billion for existing wind and no $\mathrm{CO} 2$ cost in 2018. Under a tax regulation, that increase becomes approximately $22 \%$.

- Each $10 \%$ penetration (7,540 MW) adds approximately $1.7 \%$ to the total cost reference cost when the $\mathrm{CO} 2$ cap-and-trade price is $\$ 25 /$ short ton (comparing $10 \%$ and $40 \%$ bases). 
- Each $1 \%$ increase in revenue requirement equates to about $\$ 237$ million per year.

- Only the CO2 reduction case (' $120 / 50$ ') has emissions that approach the cap by substituting gas for coal generation.

- At the $10 \%$ penetration level, operating Nebraska as a stand-alone market (rather than as a part of the SPP market) raises the SPP-wide cost (including Nebraska) by $\$ 22$ million annually for either $\mathrm{CO} 2$ regulation with price at $\$ 25 /$ short ton; however, this is not considered to be a comprehensive market analysis.

- Under cap-and-trade, there is a bigger jump in cost $(9.5 \%)$ from $\$ 0$ to $\$ 25 /$ ton than from $\$ 25$ to $\$ 50 /$ ton $(6.0 \%)$. This is likely due to the loss of $13.5 \mathrm{TWh}$ exports in going from $\$ 0$ to $\$ 25 /$ ton.

- Assuming the same case dispatches for the $20 \%$ penetration case, and the same $\mathrm{CO} 2$ prices, the total costs for SPP under a tax regulation for $\mathrm{CO} 2$ (rather than cap-and-trade), are approximately $\$ 3$ billion higher at $\$ 25 /$ short ton tax for CO2 emissions and $\$ 6$ billion higher at $\$ 50 /$ short ton tax.

\section{WAPA Interface for Integration}

Scheduling WAPA firm power to Nebraska utilities proportional to load-net-wind vs. proportional-to-load may save Nebraska \$1 million, subject to Missouri River Basin management priorities.

\section{Integration Costs}

\section{Wind Integration Costs - Results}

Wind integration costs are production cost increases due to wind forecast error, wind regulating reserves and wind shape variability. The costs are typically normalized to wind energy by dividing production cost delta by total wind energy (see Methodology section for more background).

Costs to integrate wind increase with wind energy penetrations because more natural gas fired resources are used to respond to wind forecast error while the displacement of coal energy backed down for reserves. This is shown in Figure 11. SPP integration costs increase from an average of $\$ 46$ million at 10\% wind to an average of $\$ 218$ million at $40 \%$ wind penetration using the shaped proxy.

Normalized Integration Costs (as initially defined with shaped proxy ${ }^{3}$ resource) are relatively small and in a narrow range of $\$ 1.65-\$ 2.18 / \mathrm{MWh}$ in $2018 \$$ (or $\$ 1.32$ $\$ 1.75 / \mathrm{MWh}$ in 2009\$) for the multiple penetration levels and years modeled for the base case, as shown in Figure 12.

The base penetration scenarios show a consistent increase in use of gas fired resources (especially combined cycle plants) to deal with wind forecast error and increased (and

\footnotetext{
${ }^{3}$ Shaped Proxy - a proxy wind resource that uses the actual delivered shape of the wind but is perfectly known (no forecast error) and requires no additional regulating reserves.
} 
variable) reserve requirements when comparing actual wind to ideal wind runs. In accommodating wind reserves and forecast error, the Nebraska combined cycle usage increases by $18 \%$, when comparing the actual case to the ideal case at $40 \%$ wind penetration.

The initial definition of integration costs (with shaped proxy) is only capturing effects of incremental reserves for wind and wind forecast error and is not capturing shape variability costs.

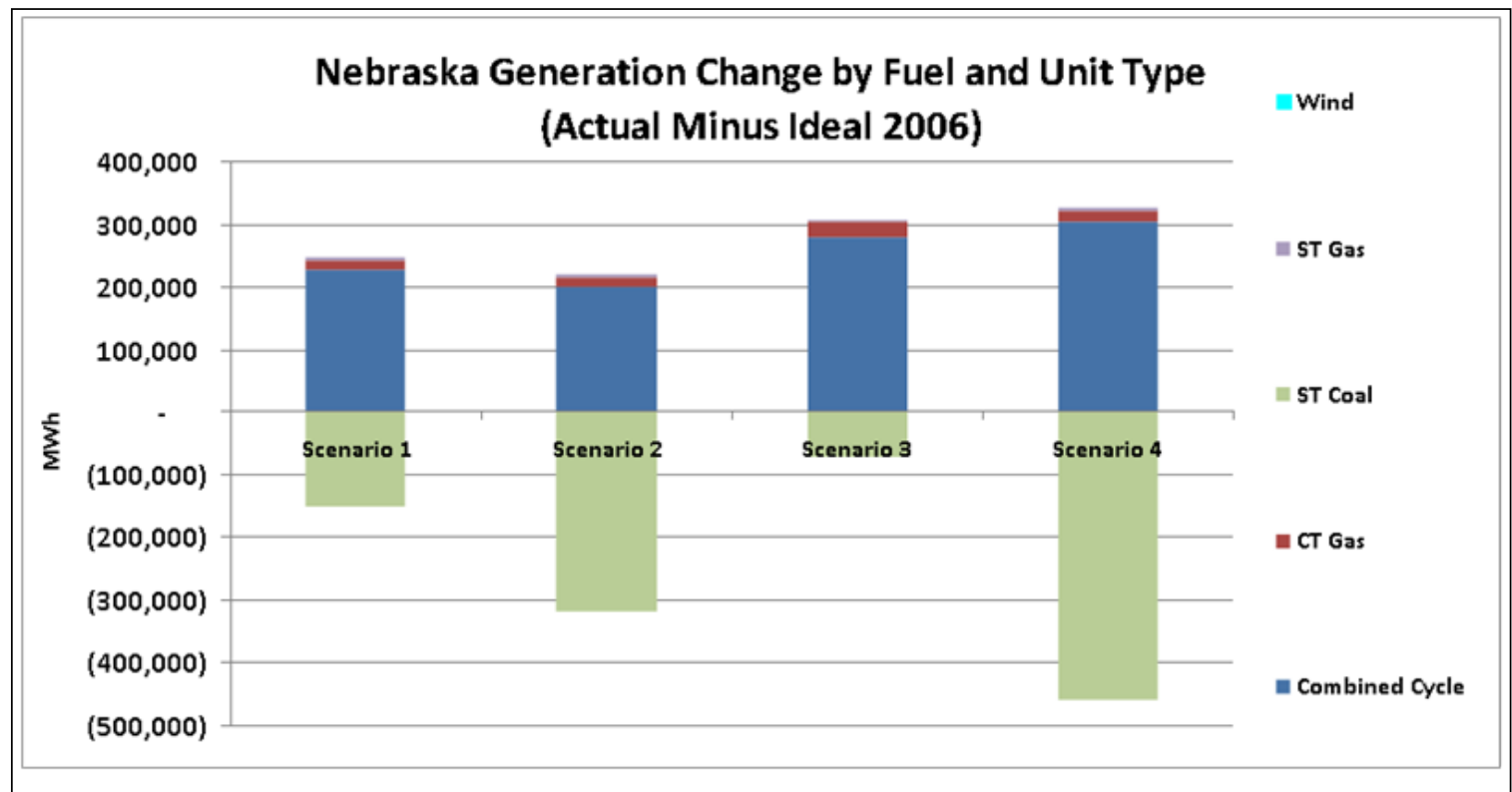

Figure 11: Change in Nebraska Generation with Incremental Reserve Requirements and Additional Uncertainty due to Wind Generation ("actual" case) 

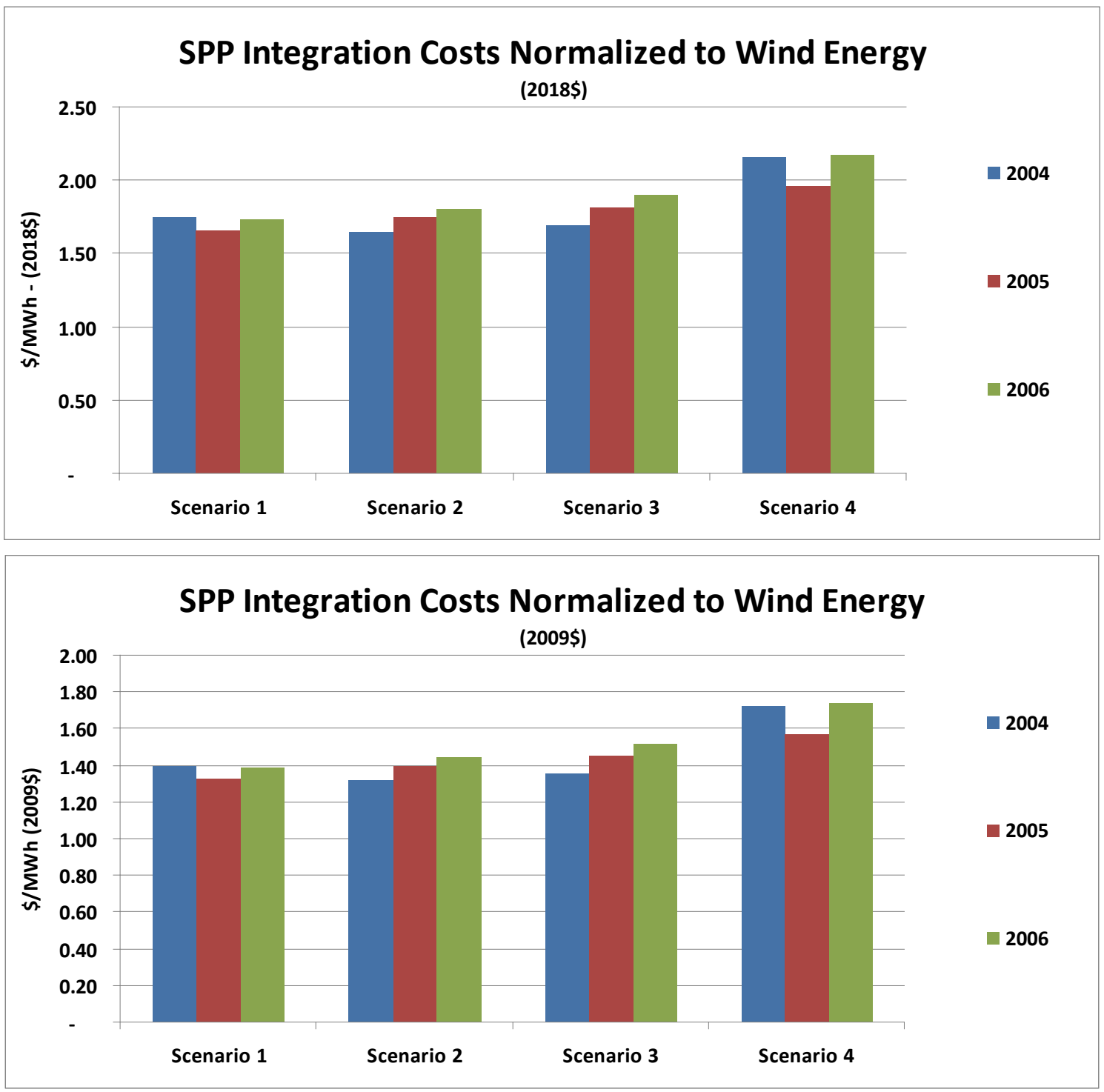

Figure 12: SPP (including Nebraska) Normalized Wind Integration Costs (shaped proxy) by Scenario and Wind Year for 2018 Conditions shown both in 2018 (top) and 2009\$ (bottom) 
Other proxy resources were tested to help measure effects of hour-to-hour wind variability on the generation fleet. Sensitivity cases show that a moving average or block (sub-period or flat) for proxy captures more integration costs, referred to as shape or variability costs, see Figure $13^{4}$.

- Proxy resource sensitivity results show $\$ 4.01 / \mathrm{MWh}$ (or $\$ 3.21 / \mathrm{MWh}$ in $2009 \$$ ) for $10 \%$ penetration with daily block proxy and $\$ 2.40 / \mathrm{MWh}$ (or $\$ 1.92 / \mathrm{MWh}$ in 2009\$) for a sub-period block proxy.

- At 20\% wind penetration, those integration cost results increase to $\$ 5.36 / \mathrm{MWh}$ (or $\$ 4.29 / \mathrm{MWh}$ in $2009 \$$ ) for the daily block proxy and $\$ 3.88 / \mathrm{MWh}(\$ 3.11 / \mathrm{MWh}$ in 2009\$) with the sub-period block proxy.

- Non-normalized integration costs using the daily block proxy for SPP are $\$ 110$ million at $10 \%$ wind and $\$ 66$ million using the sub-period block proxy; these values increase to \$286 million and \$206 million respectively for $20 \%$ wind penetration.

- These increasing differentials for alternative proxies as wind penetration increases may indicate that integration costs associated with wind variability are increasing with the amount of wind although the other costs (reserves and uncertainty as measured with the shaped proxy) are remaining relatively flat as wind penetration increases.

- Analysis indicates that the modeled system outside of SPP is absorbing some of the costs of wind variability represented in the block proxies (daily and subperiod) and that total SPP integration costs could be as high as $\$ 5.41 / \mathrm{MWh}$ $(2009 \$)$ at $10 \%$ wind penetration and $\$ 9.26 / \mathrm{MWh}(2009 \$)$ at $20 \%$ wind penetration when considering those exported costs (using the sub-period block proxy), Table 10.

${ }^{4}$ Flat block proxy consists of a 24-hour constant block of energy equal to the amount of energy of the actual wind profile for the same day. Sub period block proxy distributes the daily energy during on peak and off peak hours

Moving average proxy is a profile that represents a periodic hourly average of energy, (5 and 13 hour averages were used) 

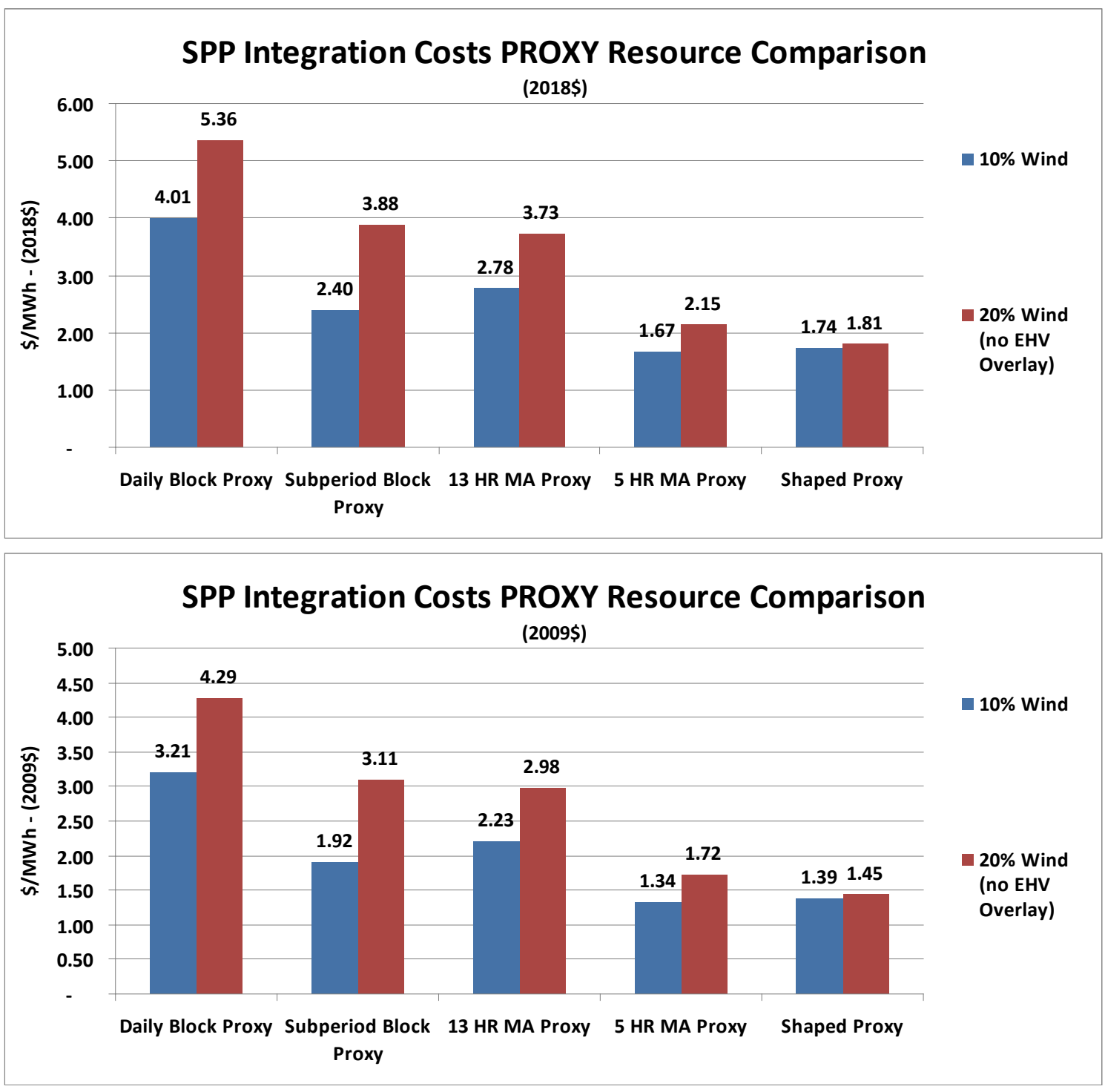

Figure 13: SPP (including Nebraska) Integration Costs Using Different Proxy Resources for 2018 Conditions shown both in $2018 \$$ (top) and $2009 \$$ (bottom) 
Table 10: Shaped and Sub-period Block Proxy Analysis at $10 \%$ and $20 \%$ Wind Penetration

\begin{tabular}{|c|c|c|c|c|}
\hline \multirow[t]{2}{*}{ Proxy Type } & \multicolumn{2}{|c|}{2018 \$/MWh } & \multicolumn{2}{|c|}{$2009 \$ / M W h$} \\
\hline & $\begin{array}{l}10 \% \text { Wind } \\
\text { Penetration }\end{array}$ & $\begin{array}{l}20 \% \text { Wind } \\
\text { Penetration }\end{array}$ & $\begin{array}{l}10 \% \text { Wind } \\
\text { Penetration }\end{array}$ & $\begin{array}{l}20 \% \text { Wind } \\
\text { Penetration }\end{array}$ \\
\hline Shaped Proxy & 1.74 & 1.81 & 1.39 & 1.45 \\
\hline $\begin{array}{l}\text { Sub-period Block Proxy -Native } \\
\text { Sub-Period Block Proxy - Implied } \\
\text { (including "exported" shape costs) }\end{array}$ & 2.4 & 3.88 & 1.92 & 3.11 \\
\hline
\end{tabular}

As discussed throughout the report, a number of cost considerations are involved with incorporating wind in addition to the wind integration costs identified in this report, such as:

- Wind generation and transmission facilities installation and operation and maintenance.

- Effects on heat rates, emission rates, and outage frequency and duration from increased thermal unit ramping. The magnitude of these effects at high penetration rates is unknown, because utilities generally do not have specific operating experience yet.

- Feasibility and pricing of highly variable exports associated with high wind penetrations.

- Effects from external areas increasing their wind penetrations along with SPP and associated reduction of external system's ability to absorb SPP wind variations.

- Lack of "shape" costs from the "shape proxy" methodology (as contained in the "daily block" proxy).

- Apparent need to consider the portion of the shape costs that get "exported" and do not show up in the calculated integration cost for the originating wind area.

\section{Wind Integration Costs - Methodology and Proxy Resource Selection}

The wind integration cost evaluation involves comparing the wind resource complete with its variability and uncertainty to an "ideal" proxy, or reference, resource by performing two simulations. The resulting adjusted production cost difference is the integration cost that can be normalized by dividing this result by the amount of wind generation being integrated. A key element in the determination of integration costs is the definition of the proxy resource. A second issue is whether or not the modeling approach addresses all the integration costs. 


\section{Conclusions}

On the first issue the report does not definitively conclude what is the single best proxy resource for establishing wind integration costs for all conditions, but indicates the subperiod block best minimizes the concerns associated with other proxies - there is minimal energy shift from off peak to on peak periods (comparing to the daily block), but shape costs are captured (comparing to the shaped proxy).

On the second issue, the report indicates that when including shape (or variability) costs by use of the block or moving average proxies, it is important to examine whether and what amount of these shape costs are being "exported" to external areas. Lastly, there are likely additional wind integration costs that are not yet identified by conventional modeling.

\section{Closing Comments}

In closing, the report must include a qualifying statement concerning how the study objectives were accomplished, and thoughts for future study are presented.

\section{Qualifying Statement}

The results, findings, and conclusions presented here relate to the scenarios defined for the calendar year 2018. Critical to these scenarios are the extensive assumptions made regarding wind generation, load, fuel prices, energy market and operational structure, and certain aspects of policy regarding carbon. While the results paint a reasonably detailed picture regarding wind integration challenges and opportunities for NPA for the scenarios studied, care must be taken in extrapolating their meaning beyond the context in which they are presented in this report.

\section{Objectives Statement}

The ten study objectives listed earlier were fully accomplished as described in the study report. Some key components were use of NREL's wind data base, wind penetration from $10 \%$ to $40 \%$, statistical and PROMOD analyses, WAPA purchase scheduled on load net wind, SPP future market, large and active TRC, active utility and stakeholder participation in Nebraska, various approaches to integration cost evaluation, use of technical experts, and transfer of data to the utilities.

\section{Thoughts for Future Study}

Detailed thoughts are offered in the study report on what might be important and productive areas to investigate further if the opportunity should arise. In summary, these areas relate to:

- Additional work on integration cost concerning proxy resource definition, influence of interchange, influence of wind penetration in external areas, and influence of hurdle rate. 
- More examinations of hourly specifics for generators and interchange, high wind/low load and low wind/high load periods, and extreme ramping situations.

- Transmission design, land use studies, and export studies.

- More wind capacity valuations, outside the current SPP criteria.

- More completely involve operational and transmission personnel. 


\section{REPORT DOCUMENTATION PAGE}

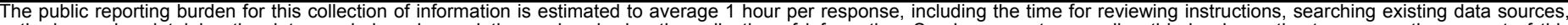

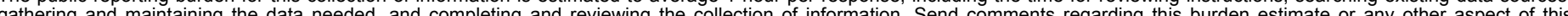

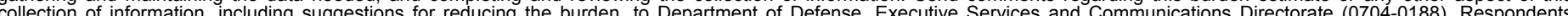

should be aware that notwithstanding any other provision of law, no person shall be subject to any penalty for fail

should be aware that notwithstanding

PLEASE DO NOT RETURN YOUR FORM TO THE ABOVE ORGANIZATION.
1. REPORT DATE (DD-MM-YYYY)
2. REPORT TYPE
March 2010
Subcontract Report
3. DATES COVERED (From - To) $4 / 2008$ to $1 / 2010$

4. TITLE AND SUBTITLE

Nebraska Statewide Wind Integration Study: Executive Summary,

April 2008 - January 2010

5a. CONTRACT NUMBER

DE-AC36-08-GO28308

5b. GRANT NUMBER

5c. PROGRAM ELEMENT NUMBER

6. AUTHOR(S)

C. Johannes and D. Kallesen

5d. PROJECT NUMBER

NREL/SR-550-47285

5e. TASK NUMBER

WE10.4311

5f. WORK UNIT NUMBER

7. PERFORMING ORGANIZATION NAME(S) AND ADDRESS(ES)

Nebraska Power Association

P.O. Box 49

8. PERFORMING ORGANIZATION REPORT NUMBER

Columbus, NE 68602-0499

AAM-9-89030-01

9. SPONSORING/MONITORING AGENCY NAME(S) AND ADDRESS(ES)

National Renewable Energy Laboratory

1617 Cole Blvd.

Golden, CO 80401-3393

10. SPONSOR/MONITOR'S ACRONYM(S)

NREL

11. SPONSORING/MONITORING AGENCY REPORT NUMBER NREL/SR-550-47285

12. DISTRIBUTION AVAILABILITY STATEMENT

National Technical Information Service

U.S. Department of Commerce

5285 Port Royal Road

Springfield, VA 22161

13. SUPPLEMENTARY NOTES

NREL Technical Monitor: Brian Parsons

14. ABSTRACT (Maximum 200 Words)

Wind generation resources in Nebraska will play an increasingly important role in the environmental and energy security solutions for the state and the nation. In this context, the Nebraska Power Association conducted a statewide wind integration study.

\section{SUBJECT TERMS}

Nebraska; wind; integration study; Nebraska Power Association.

16. SECURITY CLASSIFICATION OF:
\begin{tabular}{|l|l|l|}
\hline a. REPORT & b. ABSTRACT & c. THIS PAGE \\
Unclassified & Unclassified & Unclassified \\
& & \\
\hline
\end{tabular}

\begin{tabular}{|c|c|}
\hline $\begin{array}{l}\text { 17. LIMITATION } \\
\text { OF ABSTRACT }\end{array}$ & $\begin{array}{l}\text { 18. NUMBER } \\
\text { OF PAGES }\end{array}$ \\
\hline UL & \\
\hline
\end{tabular}

19a. NAME OF RESPONSIBLE PERSON

19b. TELEPHONE NUMBER (Include area code) 